\title{
A Bibliographic Analysis of Transformer Literature 1990-2000
}

\author{
J. C. Olivares-Galvan ${ }^{1}$, R. Escarela-Perez ${ }^{1}$, P. S. Georgilakis ${ }^{2}$, I. Fofana ${ }^{3, *}$, Salvador Magdaleno-Adame ${ }^{4}$ \\ ${ }^{1}$ Depart. de Energia, Universidad Autonoma Metropolitana, Ciudad de Mexico, D.F. Mexico \\ ${ }^{2}$ School of Electrical and Computer Engineering, National Technical University of Athens (NTUA), Athens, Greece \\ ${ }^{3}$ Canada Research Chair on Insulating Liquids and Mixed Dielectrics for Electrotechnology (ISOLIME), Université du Québec à \\ Chicoutimi, Québec, Canada \\ ${ }^{4}$ Instituto Tecnologico de Morelia, Av. Tecnologico \#1500, Colonia Lomas de Santiaguito, 58120, Morelia Michoacan, Mexico
}

\begin{abstract}
This paper presents an analysis of the bibliography on transformers covering the period from 1990 to 2000. It contains all the transformer subjects: a) Transformer design, b) Transformer protection, c) Transformer connections, d) Transformer diagnostics, e) Transformer failures, f) Transient analysis of transformers (overvoltages, overcurrents), g) Modeling and analysis of transformer using FEM (thermal modeling, losses modeling, insulation modeling, windings modeling). Several international journals were investigated including the following: Advances in Electrical and Computer Engineering, Canadian Journal of Electrical and Computer Engineering, COMPEL (The International Journal for Computation and Mathematics in Electrical and Electronic Engineering), Electrical Engineering, Electric Power Components and Systems, Electric Power Systems Research, European Transactions on Electrical Power, IEEE Transactions on Magnetics, IEEE Transactions on Power Delivery, International Journal of Electrical Power and Energy Systems, and IET Generation Transmission \& Distribution. Due to the high number of publication in journals, we are not considering publications of conferences and symposia. A total of 700 publications are analyzed in this paper. The research presented in this paper is important because it contains and analyzes the best research papers on transformers coming from many countries all over the world and published in top rated scientific electrical engineering journals.
\end{abstract}

Keywords Connection, Design, Diagnostics, Failure, Protection, Transformer, Transient Analysis

\section{Introduction}

This paper analyzes publications of all the different subje cts of transformer, e.g.: a) Transformer design, b) Transformer protection, c) Transformer connections, d) Transformer diagnostics, e) Transformer failures, f) Transient analysis of transformers (overvoltages, overcurrents), g) Modeling and analysis of transformer using FEM (thermal modeling, losses modeling, insulation modeling, windings modeling). All electrical engineering journals in English are included. All journals investigated are shown in Table 1. The analysis of publications can help assess the productivity and impact of authors, institutions, and countries in worldwide transformer research.

\section{Methodology for Analyzing Transformer Bibliography}

All publications on transformers were downloaded from the respective Internet sites of the journals and the following

* Corresponding author:

ifofana@uqac.ca (I. Fofana)

Published online at http://journal.sapub.org/eee

Copyright (C) 2012 Scientific \& Academic Publishing. All Rights Reserved elements were stored in a database: journal name, year of publication, paper title, number of citations, name of first author, affiliation of first author, and country of first author. In this contribution only research papers were considered, including original research papers, reviews, and letters. To assess the impact of these papers, we downloaded citation information, during December 2010, from Google Scholar (including self-citations). We preprocessed the collected data for bibliographic analysis by crediting each paper to its first author. This means that if a paper has more than one author, then the paper is credited to its first author, i.e., the paper is credited to the name of the first author, to the affiliation of the first author, and to the country of the first author. If the first author has more than one affiliation, we consider only the first affiliation of this author.

Table 2 shows the most cited papers from 1990 to 2000. Obviously in these outstanding papers in terms of citations received, the names of all authors are presented in the third column of that table. It can be seen in Table 2 that the three most cited papers accumulate a total of 420 citations. Moreover, these three most cited papers are related to the diagnosis of transformers. The three most cited papers have an average of 7 to 11 citations per year starting from the date of their publication. 
Table 1. Electrical engineering journals investigated (journals are listed in alphabetical order)

\begin{tabular}{|c|}
\hline $\begin{array}{c}\text { Advances in Electrical and Computer Engineering } \\
\text { Canadian }\end{array}$ \\
\hline $\begin{array}{l}\text { COMPEL (The International Journal for Computation and Mathe- } \\
\text { matics in Electrical and Electronic Engineering) }\end{array}$ \\
\hline Electrical Engineering \\
\hline Electric Power Components and Systems \\
\hline Electric Power Systems Research \\
\hline European Transactions on Electrical Power \\
\hline IEEE Computer Applications in Power Magazine \\
\hline IEEE Transactions on Applied Superconductivity \\
\hline IEEE Transactions on Dielectrics and Electrical Insulation \\
\hline IEEE Transactions on Education \\
\hline IEEE Transactions on Energy Conversion \\
\hline IEEE Transactions on Industry Applications \\
\hline IEEE Transactions on Magnetics \\
\hline IEEE Transactions on Power Delivery \\
\hline IEEE Transactions on Power Systems \\
\hline IET Electric Power Applications \\
\hline IET Generation Transmission \& Distribution \\
\hline IET Science Measurement \& Technology \\
\hline International Journal of Electrical Power \& Energy Systems \\
\hline International Review of Electrical Engineering-IREE \\
\hline Journal of Magnetism and Magnetic Materials \\
\hline
\end{tabular}

\section{Outstanding Papers, Authors, Institutions and Journals from 1990 to 2000}

Tables 3 to 5 show the most productive countries, institutions, and authors, respectively, from 1990 to 2000. It may be concluded that research on transformers was dominated by USA and Japan researchers (see Table 3). Tokyo Electric Power (Japan), General Electric (USA), and Department of Electrical Engineering of Toronto University (Canada) are the three most productive institutions (see Table 4). According to the analysis, Pierce, de Leon, and Arturi are the three most productive authors with 19 publications in total (see Table 5). It can be seen from Table 6 that 475 papers on transformers have been published in IEEE Journals, i.e., $68 \%$ of the total 700 publications on transformers collected from the period from 1990 to 2000 .

Table 2. Most cited papers from 1990 to 2000

\begin{tabular}{|c|c|c|c|c|c|}
\hline Rank & Title & Authors & Year & Country & Cites \\
\hline 1 & $\begin{array}{c}\text { "An artificial neural network approach to transformer fault } \\
\text { diagnosis" }\end{array}$ & Zhang, Y. & 1996 & USA & 175 \\
\hline 2 & $\begin{array}{c}\text { "An expert system for transformer fault diagnosis using } \\
\text { dissolved gas analysis" }\end{array}$ & Lin, C.E.; Ling, J.-M.; Huang, C.-L.; & 1993 & China & 130 \\
\hline 3 & $\begin{array}{c}\text { "Developing a new transformer fault diagnosis system through } \\
\text { evolutionary fuzzy logic" }\end{array}$ & Yann-Chang Huang & 1997 & Taiwan & 115 \\
\hline 4 & "A high frequency transformer model for the EMTP" & Morched, A.; Marti, L.; Ottevangers, J.; & 1993 & Canada & 98 \\
\hline 5 & "A transformer model for winding fault studies" & Bastard, P.; Bertrand, P.; Meunier, M.; & 1994 & France & 98 \\
\hline 6 & $\begin{array}{c}\text { "A combined ANN and expert system tool for transformer } \\
\text { fault diagnosis" }\end{array}$ & Zhenyuan Wang Yilu Liu Griffin & 1998 & USA & 96 \\
\hline 7 & $\begin{array}{l}\text { "Improved simulation models for current and voltage trans- } \\
\text { formers in relay studies" }\end{array}$ & $\begin{array}{l}\text { Lucas, J.R.; McLaren, P.G.; Keerthi- } \\
\text { pala, W.W.L.; Jayasinghe, R.P.; }\end{array}$ & 1992 & $\begin{array}{c}\text { Sri } \\
\text { Lanka }\end{array}$ & 93 \\
\hline 8 & $\begin{array}{l}\text { "Power differential method for discrimination between fault } \\
\text { and magnetizing inrush current in transformers" }\end{array}$ & Yabe, $\mathrm{K}$. & 1997 & Japan & 88 \\
\hline 9 & "Status and trends in transformer monitoring" & Bengtsson, C. & 1996 & Sweden & 86 \\
\hline 10 & "Complete transformer model for electromagnetic transients" & de Leon, F.; Semlyen, A.; & 1994 & Canada & 83 \\
\hline
\end{tabular}

Table 3. Most productive countries from 1990 to 2000

\begin{tabular}{|c|c|c|}
\hline Rank & Country & Counts \\
\hline 1 & USA & 183 \\
\hline 2 & Japan & 55 \\
\hline 3 & Canada & 47 \\
\hline 4 & China & 36 \\
\hline 5 & United Kingdom & 33 \\
\hline 6 & France & 30 \\
\hline 7 & Poland & 22 \\
\hline 8 & Germany & 19 \\
\hline 9 & Italy & 18 \\
\hline 10 & India & \\
\hline
\end{tabular}

Table 4. Most productive institutions from 1990 to 2000 (taking into account only the affiliation of the first author)

\begin{tabular}{|c|r|c|}
\hline Rank & Institution & Counts \\
\hline 1 & Tokyo Electric Power Co., Ltd. & 10 \\
\hline 2 & General Electric Co., Rome, Georgia & 8 \\
\hline 3 & Dept. of Electr. Eng., Toronto Univ., Ont. & 7 \\
\hline 4 & Dept. of Electr. Power Eng., Rensselaer Polytech. Inst., Troy, NY & 7 \\
\hline 5 & Chubu Electric Power Co., Inc. Nagoya, Japan & 6 \\
\hline 6 & Coll. of Eng., Idaho State Univ., Pocatello, ID & 6 \\
\hline 7 & Dipartimento di Elettrotecnica, Politecnico di Milano & 6 \\
\hline 8 & Dept. of Electr. \& Electron. Eng., Tokyo Inst. of Technol., Japan & 5 \\
\hline 9 & Amorphous Magnetic Device Lab., Sendai & 4 \\
\hline 10 & Cooper Power Syst., Pewaukee, WI & 4 \\
\hline 11 & Dept. of Electr. Eng., Arizona State Univ., Tempe, AZ & 4 \\
\hline 12 & Dept. of Electr. Eng., British Columbia Univ., Vancouver, BC & 4 \\
\hline 13 & Dept. of Electr. Eng., Ohio State Univ., Columbus, OH & 4 \\
\hline 14 & Dept. of Electr. Eng., Southeast Univ., Nanjing & 4 \\
\hline 15 & Inst. de Recherche, IREQ, Varennes, Que. & 4 \\
\hline
\end{tabular}


Table 5. Most productive authors from 1990 to 2000 (taking into account only the affiliation of the first author)

\begin{tabular}{|c|c|c|c|c|}
\hline Rank & Name & Affiliation & Counts & Country \\
\hline 1 & Pierce, L.W.; & General Electric Co., Rome, GA & 8 & USA \\
\hline 2 & de Leon, F.; Semlyen, A.; & Inst. Politecnico Nacional, Mexico City & 6 & Mexico \\
\hline 3 & Arturi, C.M.; & Dipartimento di Elettrotecnica, Politecnico di Milano & 5 & Italy \\
\hline 4 & $\begin{array}{l}\text { Lin, C.E.; Yeh, J.C.; Huang, C.L.; Cheng, } \\
\text { C.L.; }\end{array}$ & Dept. of Electr. Eng., Cheng Kung Univ., Taiwan & 5 & China \\
\hline 5 & Tsujimoto, H.; Wada, T.; Shirae, K.; & $\begin{array}{l}\text { Fac. of Eng. Sci., Osaka Univ. } \\
\end{array}$ & 5 & Japan \\
\hline 6 & Yamaguchi, H.; Sato, Y.; Kataoka, T.; & Dept. of Electr. \& Electron. Eng., Tokyo Inst. of Technol., Japan & 5 & Japan \\
\hline 7 & Kasztenny, B. & Texas A\&M Univ., College Station, TX & 4 & USA \\
\hline 8 & Koppikar, D.A. & Transformer Div., Crompton Greaves Ltd., Kanjur & 4 & India \\
\hline 9 & $\begin{array}{l}\text { Tang Renyuan; Yang Junyou; Lin Feng; Lu } \\
\text { Yongping; }\end{array}$ & Res. Inst. of Special Electr. Machines, Shenyang Polytech. Univ. & 4 & China \\
\hline 10 & Blue, $\mathrm{R}$. & Strathclyde Univ., Glasgow & 3 & $\begin{array}{c}\text { United } \\
\text { Kingdom }\end{array}$ \\
\hline 11 & Brubaker, M.A.x & Los Alamos Nat. Lab., NM & 3 & USA \\
\hline 12 & $\begin{array}{l}\text { Cui Xiang; Lui Jianxin; Xie Yucheng; He } \\
\text { Ronggui; Zhang Guoqiang; Yang Chunping }\end{array}$ & Dept. of Electr. Eng., North China Inst. of Electr. Power & 3 & China \\
\hline 13 & E. Leśniewska and Z. Kowalski & University Warsawa, Poland & 3 & Poland \\
\hline 14 & Ebert, J.A.; & MagneTek Electr., Waukesha, WI & 3 & USA \\
\hline 15 & Elleuch, M. & Lab. des Syst. Electr., Ecole Nat. d'Ingenieurs, Tunis & 3 & Tunisia \\
\hline
\end{tabular}

Table 6. Most productive journals from 1990 to 2000

\begin{tabular}{|c|c|c|}
\hline Rank & Journals & Counts \\
\hline 1 & IEEE Transactions on Power Delivery & 243 \\
\hline 2 & IEEE Transactions on Magnetics & 158 \\
\hline 3 & IEEE Transactions on Industry Applications & 35 \\
\hline 4 & COMPEL & 31 \\
\hline 5 & Electric Power Systems Research & 22 \\
\hline 6 & IET Science Measurement \& Technology & 22 \\
\hline 7 & IET Generation, Transmission and Distribution & 21 \\
\hline 8 & IEEE Transactions on Dielectrics and Electrical & 20 \\
\hline 9 & Insulation & 19 \\
\hline 10 & EEEE Transactions on Applied Superconductivity & 16 \\
\hline
\end{tabular}

\section{Conclusions}

This paper assesses the state of transformer research based on the publications in the main electrical engineering journals during the decade of 1990-2000. It was found that USA and Japan researchers dominate transformer research. Following USA and Japan, Canadian researchers have also published a significant number of papers. The three most cited papers have an average of 7 to 11 citations per year and these papers are from USA, China, and Taiwan, respectively. Pierce, de Leon, and Arturi are the three most productive authors. Tokyo Electric Power (Japan), General Electric (USA), and Department of Electrical Engineering of Toronto University (Canada) are the three most productive institutions. Our results of ranking should not be viewed as definitive. This publication is the starting point of many different ways to interpret the transformer research in many electrical engineering journals. We hope that in the near future this kind of information will keep moving. Bear in mind that this bibliographic research work may contain omissions. Basically, Table 5 should be more exhaustive by including co-authors. Some of the authors have certainly co-authored papers not as first authors. An alternative way should be investigated by assigning to each author a coefficient depending on the total number of authors.

The authors are still engaged in future work aiming at establishing a web search engine to investigate information presented in this contribution. This information would be presented and updated automatically using this web search engine.

\section{REFERENCES}

[1] J. Bornemann, "Design of millimetre-wave diplexers with optimized H-plan transformer sections," Canadian Journal of Electrical and Computer Engineering, vol. 15, no. 1, pp. 5-8, 1990

[2] K. Zakrzewski, M. Lukaniszyn, "Three-dimensional model of three-phase transformer for leakage field calculation," Electrical Engineering, vol. 73, no. 5, pp. 319-324, 1990

[3] H.K. Verma, A.M. Basha, "Microprocessor-based comprehensive relaying scheme for power transformer protection," Electric Power Systems Research, vol. 19, no. 2, pp. 115-127, 1990

[4] A. A. Girgis, E. B. Makram, J. W. Nims, L. K. O'Dell, "Evaluation of temperature rise of distribution transformers in the presence of harmonics and distortion," Electric Power Systems Research, vol. 20, no. 1, pp. 15-22, 1990

[5] R.J. Rusch, M.L. Good, "Wyes and wye nots of three-phase distribution transformer connections," IEEE Transactions on Industry Applications, vol. 26, no. 4, pp. 683-688, 1990

[6] C.T. Rim, D.Y. Hu, G.H. Cho, "Transformers as equivalent circuits for switches: general proofs and D-Q transformation-based analyses," IEEE Transactions on Industry Applications, vol. 26, no. 4, pp. 777-785, 1990

[7] T. Renyuan, Y. Junyou, W. Zhouxiong, L. Feng, L. Chunrong, $\mathrm{X}$. Zihong, "Computation of eddy current losses by heavy current leads and windings in large transformers using IEM coupled with improved R- $\psi$ method," IEEE Trans. Magn., 
vol. 26, no. 2, pp. 493-496, 1990

[8] R. De Rochebrune, J.M. Dedulle, J.C. Sabonnadiere, "A technique of homogenization applied to the modelling of transformers," IEEE Trans. Magn., vol. 26, no. 2, pp. 520-523, 1990

[9] T. Ngnegueu, G. Meunier, J.C. Sabonnadiere, M. Mailhot, J.P. Arthaud, "2-D finite element calculation of shell losses in power transformers, taking the third dimension into account by means of a correction factor," IEEE Trans. Magn., vol. 26, no. 2, pp. 925-928, 1990

[10] K. Yamasawa, P.P. Biringer, "Application of a new orthogonal-flux-type amorphous core to high-frequency parametric inverters and three-phase measuring transformers," IEEE Trans. Magn., vol. 26, no. 3, pp. 1198-1203, 1990

[11] T. Matsuura, K. Nagayama, S. Hagiwara, M. Higaki, "Long-term reliability of iron-based amorphous alloy cores for oil-immersed transformers," IEEE Trans. Magn., vol. 26, no. 5, pp. 1993-1995, 1990

[12] A. Nafalski, G. Matras, A. Wac-Wlodarczyk, H. Stryczewska, "Aging tests of amorphous current transformers used in ground fault interrupters," IEEE Trans. Magn., vol. 26, no. 5, pp. 2005-2007, 1990

[13] J. Turowski , M. Turowski, M. Kopec, "Method of three-dimensional network solution of leakage field of three-phase transformers," IEEE Trans. Magn., vol. 26, no. 5, pp. 2911-2919, 1990

[14] P. Sankaran, V.J. Kumar, V. Jayashankar, "Error estimation of current transformers using single or composite cores of ferromagnetic materials," IEEE Trans. Magn., vol. 26, no. 6, pp. 3086-3088, 1990

[15] A. Keyhani, H. Tsai, A. Abur, "Maximum likelihood estimation of high frequency machine and transformer winding parameters," IEEE Trans. Power Delivery, vol. 5, no. 1, pp. 212-219, 1990

[16] Y. Inoue, K. Suganuma, M. Kamba, M. Kikkawa, "Development of oil-dissolved hydrogen gas detector for diagnosis of transformers," IEEE Trans. Power Delivery, vol. 5, no. 1, pp. 226-232, 1990

[17] G.J. Golub, "Specifying bar codes for distribution transformers: a guideline," IEEE Trans. Power Delivery, vol. 5, no. 1, pp. 233-238, 1990

[18] A.B.P. Joosten, J. Arrillaga, C.P. Arnold, N.R. Watson, "Simulation of HVDC system disturbances with reference to the magnetizing history of the convertor transformers," IEEE Trans. Power Delivery, vol. 5, no. 1, pp. 320-336, 1990

[19] O. Bourgault, G. Morin, "Analysis of a harmonic overvoltage due to transformer saturation following load shedding on Hydro-Quebec-NYPA $765 \mathrm{kV}$ interconnection," IEEE Trans. Power Delivery, vol. 5, no. 1, pp. 397-405, 1990

[20] J.F. Baranowski, G.L. Goedde, "Distribution transformer BIL reduction feasibility study," IEEE Trans. Power Delivery, vol. 5, no. 1, pp. 509-513, 1990

[21] T. Sawa, K. Kurosawa, T. Kaminishi, T. Yokota, "Development of optical instrument transformers," IEEE Trans. Power Delivery, vol. 5, no. 2, pp. 884-891, 1990

[22] T.V. Oommen, S.R. Lindgren, "Streaming electrification study of transformer insulation system using a paper tube model," IEEE Trans. Power Delivery, vol. 5, no. 2, pp. 972-983, 1990

[23] L.M. Burrage, J.H. Shaw, B.W. McConnell, "Distribution transformer performance when subjected to steep front impulses," IEEE Trans. Power Delivery, vol. 5, no. 2, pp. 984-990, 1990

[24] G.L. Alegi, W.Z. Black, "Real-time thermal model for an oil-immersed, forced-air cooled transformer," IEEE Trans. Power Delivery, vol. 5, no. 2, pp. 991-999, 1990

[25] E. Howells, M. Zahn, S.R. Lindgren, "Static electrification effects in transformer oil circulating pumps," IEEE Trans. Power Delivery, vol. 5, no. 2, pp. 1000-1006, 1990

[26] L.R. Stuffle, R.E. Stuffle, "A computerized diagnostic technique applicable to HV impulse testing of transformers," IEEE Trans. Power Delivery, vol. 5, no. 2, pp. 1007-1012, 1990

[27] IEEE PES Power Eng. Relaying Comm, Network Transformer Protection Working Group, "Summary of IEEE Guide for the Protection of Network Transformers," IEEE Trans. Power Delivery, vol. 5, no. 3, pp. 1288-1291, 1990.

[28] Y.V.V.S. Murty, W.J. Smolinski, "A Kalman filter based digital percentage differential and ground fault relay for a 3-phase power transformer," IEEE Trans. Power Delivery, vol. 5, no. 3, pp. 1299-1308, 1990

[29] A. Hamel, G. St-Jean, M. Paquette, "Nuisance fuse operation on MV transformers during storms," IEEE Trans. Power Delivery, vol. 5, no. 4, pp. 1866-1864, 1990

[30] J. Aubin, R. Bergeron, R. Morin, "Distribution transformer overloading capability under cold-load pickup conditions," IEEE Trans. Power Delivery, vol. 5, no. 4, pp. 1883-1891, 1990

[31] R.C. Dugan, S.S.Jr. Kershaw, S.D. Smith, "Protecting distribution transformers from low-side current surges," IEEE Trans. Power Delivery, vol. 5, no. 4, pp. 1892-1901, 1990

[32] E. Leśniewska, Z. Kowalski, "Designing voltage transformer insulation systems with $\mathrm{SF}_{6}$-insulations using $\mathrm{CAD}$," Electrical Engineering, vol. 74, no. 6, pp. 427-432, 1991

[33] E. Laveuve, J. P. Keradec, G. Meunier, "Influence of induced currents in conductors on leakage and losses in a transformer," Electric Power Components and Systems, vol. 19, no. 1, pp. 55-68, 1991

[34] B. S. Ashok Kumar, S. Ertem, "Capacitor voltage transformer induced ferroresonance - causes, effects and design considerations," Electric Power Systems Research, vol. 21, no. 1, pp. 23-31, 1991

[35] E. E. Mombello, G. Rattá, J. F. Rivera, "Study of internal stresses in transformer windings due to lightning transient phenomena," Electric Power Systems Research, vol. 21, no. 2, pp. 161-172, 1991

[36] A. J. Kachler, R. Maier, H. Nieschwietz, "Validity of narrow and broadband pd-measurements on power transformers; pulse deformations," European Transactions on Electrical Power, vol. 1, no. 2, pp. 113-118, 1991

[37] S.R. Mendis, M.T. Bishop, D.A. Gonzalez, "Rule-based coordination program evaluates distribution transformer 
overcurrent protection alternatives," IEEE Computer Applications in Power Magazine, vol. 4, no. 2, pp. 31-36, 1991

[38] Y. Kamata, A. Miki, S. Furukawa, "A singular flashover path observed on the surface of synthetic-resin-bonded paper cylinders immersed in transformer oil under switching impulse voltage conditions," IEEE Trans. Electr. Insul., vol. 26, no. 2, pp. 300-310, 1991

[39] M.M. Saied, A.A. Hanafy, M.A. El-Gabaly, Y.A. Safar, M.G. Jaboori, K.A. Yamin, A.M. Sharaf, "Optimal design parameters for a PV array coupled to a DC motor via a DC-DC transformer," IEEE Transactions on Energy Conversion, vol. 6, no. 4, pp. 593-598, 1991

[40] I. Kerszenbaum, A. Mazur, M. Mistry, J. Frank, "Specifying dry-type distribution transformers for solid-state applications,' IEEE Transactions on Industry Applications, vol. 27, no. 1, pp. 173-178, 1991

[41] H.A. Kojori, S.B. Dewan, J.D. Lavers, "Steady-state analysis and design optimization of an inductor-transformer resonant DC-DC converter," IEEE Transactions on Industry Applications, vol. 27, no. 3, pp. 515-522, 1991

[42] D.E. Johnson, N.D. Clements, "Opening switches for a 5 MJ, 1 MA energy storage transformer," IEEE Trans. Magn., vol. 27, no. 1, pp. 421-425, 1991

[43] D.E. Johnson, N.D. Clements, "Lightweight high-efficiency energy-storage transformers," IEEE Trans. Magn., vol. 27, no. 1, pp. 426-428, 1991

[44] T. Isono, Y. Takahashi, K. Yoshida, K. Okuno, N. Koizumi, M. Sugimoto, M. Nishi, H. Nakajima, T. Iliyama, T. Kato, K. Kanano, H. Hiue, M. Ono, E. Kawagoe, H. Ishida, J. Yoshida, Y. Kamiyauchi, M. Oshikiri. H. Ilanawa, H. Ohuchi, T. Ohuchi, F. Tajiri, T. Hosoya, N. Watahiki, T. Ando, H.Tsuji, M. Konno, T. Uede, I. Itoh, K. Sakaki, N. Aoki, E.Suzuki, "Critical current measurements using 13-T split coils and 100-kA superconducting transformer [for FER]," IEEE Trans. Magn., vol. 27, no. 2, pp. 1839-1842, 1991

[45] M. Iwakuma, K. Funaki, M. Takeo, K. Yamafuji, "Quench protection of superconducting transformers," IEEE Trans. Magn., vol. 27, no. 2, pp. 2080-8083, 1991

[46] F.C. Wellstood, J.J. Kingston, M.J. Ferrari, J. Clarke, "Thin-film flux transformers of $\mathrm{YBa}_{2} \mathrm{Cu}_{3} \mathrm{O}_{7-\mathrm{x}}$," IEEE Trans. Magn., vol. 27, no. 2, pp. 2569-2572, 1991

[47] H. Inoue, Y. Okada, "Finite element analysis of crosstalk in a rotary transformer for VCRs," IEEE Trans. Magn., vol. 27, no. 5, pp. 3931-3934, 1991

[48] J. Sakellaris, Y. Marechal, G. Meunier, "Techniques for computing the sheet winding transformers ohmic losses using numerical and analytical methods," IEEE Trans. Magn., vol. 27, no. 5, pp. 3943-3946, 1991

[49] R. Wang, N. Demerdash “A combined vector potential-scalar potential method for FE computation of 3D magnetic fields in electrical devices with iron cores," IEEE Trans. Magn., vol. 27, no. 5, pp. 3971-3977, 1991

[50] J.P. Keradec, E. Laveuve, J. Roudet, "Multipolar development of vector potential for parallel wires. Application to the study of eddy currents effects in transformer windings," IEEE Trans. Magn., vol. 27, no. 5, pp. 4242-4245, 1991

[51] S. Toitot, G. Meunier, J. Sakellaris, J.C. Sabonnadiere,
"Two-dimensional transformer modeling taking into account the edge effects by introduction of a correction factor," IEEE Trans. Magn., vol. 27, no. 6, pp. 4998-4999, 1991

[52] A. Basak, A.J. Moses, M.R. Yasin, "Effect of stacking method and clamping on distribution transformers built with amorphous magnetic material," IEEE Trans. Magn., vol. 27, no. 6 , pp. 5196-5198, 1991

[53] S. Hayano, Y. Nakajima, H. Saotome, Y. Saito, "A new type high frequency transformer," IEEE Trans. Magn., vol. 27, no. 6, pp. 5205-5207, 1991

[54] R.H. Vander Heiden, A.A. Arkadan, J.R. Brauer, "Finite element modeling of a transformer feeding a rectified load: the coupled power electronics and nonlinear magnetic field problem," IEEE Trans. Magn., vol. 27, no. 6, pp. 5217-5219, 1991

[55] I. Daut, A.J. Moses, "Some effects of clamping pressure on localised losses and flux distribution in a transformer core assembled from POWERCORE strip," IEEE Trans. Magn., vol. 27 , no. 6 , pp. 5262-5264, 1991

[56] R. Passaglia, S. Zannella, "Stacked transformer cores using amorphous POWERCORE strip," IEEE Trans. Magn., vol. 27, no. 6, pp. 5265-5267, 1991

[57] H. Tsujimoto, Y. Nozawa, K. Shirae, "Pinhole device: a new type of thin film transformer," IEEE Trans. Magn., vol. 27, no. 6, pp. 5271-5273, 1991

[58] I. Hermanto, Y. V. V. S. Murty, M.A. Rahman, "A stand-along digital protective relay for power transformers," IEEE Trans. Power Delivery, vol. 6, no. 1, pp. 85-95, 1991

[59] J.A.C. Forrest, "Harmonic load losses in HVDC converter transformers," IEEE Trans. Power Delivery, vol. 6, no. 1, pp. $153-157,1991$

[60] Jung-Chien Li, Yan-Pei Wu, "FFT algorithms for the harmonic analysis of three-phase transformer banks with magnetic saturation," IEEE Trans. Power Delivery, vol. 6, no. 1, pp. 158-165, 1991

[61] H. Mohseni, "Multi-winding multi-phase transformer model with saturable core," IEEE Trans. Power Delivery, vol. 6, no. 1, pp. 166-173, 1991

[62] C.M. Arturi, "Transient simulation and analysis of a three-phase five-limb step-up transformer following an out-of-phase synchronization," IEEE Trans. Power Delivery, vol. 6 , no. 1, pp. 196-207, 1991

[63] Y. Kito, H. Okubo, N. Hayakawa, Y. Mita, M. Yamamoto, "Development of a $6600 \mathrm{~V} / 210 \mathrm{~V}$ kVA hybrid-type superconducting transformer," IEEE Trans. Power Delivery, vol. 6, no. 2, pp. 816-823, 1991

[64] A. Keyhani, S.W. Chua, S.A Sebo, "Maximum likelihood estimation of transformer high frequency parameters from test data," IEEE Trans. Power Delivery, vol. 6, no. 2, pp. $858-865,1991$

[65] C.E. Lin, C.-L. Cheng, C.-L. Huang, "Hysteresis characteristic analysis of transformer under different excitations using real time measurement," IEEE Trans. Power Delivery, vol. 6, no. 2, pp. 873-879, 1991

[66] D.E Parrish, "Lightning-caused distribution transformer outages on a Florida distribution system," IEEE Trans. Power 
Delivery, vol. 6, no. 2, pp. 880-887, 1991

[67] M.D. Cox, F.C. Berry, S.N. Govindarajan, "Harmonic response tests on distribution circuit potential transformers," IEEE Trans. Power Delivery, vol. 6, no. 3, pp. 973-978, 1991

[68] G. Benmouyal, "Design of a combined digital global differential and volt/hertz relay for step-up transformers," IEEE Trans. Power Delivery, vol. 6, no. 3, pp. 1000-1007, 1991

[69] J.K. Bladow, A.H. Montoya, "Experiences with parallel EHV phase shifting transformers," IEEE Trans. Power Delivery, vol. 6, no. 3, pp. 1096-1100, 1991

[70] Y. Mukaiyama, F. Nonaka, I. Takagi, M. Higaki, K. Ehdoo, T. Sakamoto, K. Hiraishi, K. Kawashima, "Development of a perfluorocarbon liquid immersed prototype large power transformer with compressed $\mathrm{SF}_{6}$ gas insulation," IEEE Trans. Power Delivery, vol. 6, no. 3, pp. 1108-1116, 1991

[71] Y. Mukaiyama, I. Takagi, H. Ishihara, A. Kudo, Y Makino, N. Hosokawa, "Principal decomposition by-products generated at various abnormalities in gas-insulated transformers," IEEE Trans. Power Delivery, vol. 6, no. 3, pp. 1117-1123, 1991

[72] R.P. Kendig, S.E. Wright, "Validation of acoustic intensity measurements for power transformers," IEEE Trans. Power Delivery, vol. 6, no. 4, pp. 1524-1530, 1991

[73] R.A. Walling, A.N. Khan, "Characteristics of transformer exciting-current during geomagnetic disturbances," IEEE Trans. Power Delivery, vol. 6, no. 4, pp. 1707-1714, 1991

[74] M.I. Samesima, J.C. de Oliveira, E.M. Dias, "Frequency response analysis and modeling of measurement transformers under distorted current and voltage supply," IEEE Trans. Power Delivery, vol. 6, no. 4, pp. 1762-1768, 1991

[75] M.A.S. Masoum, E.F. Fuchs, D.J Roesler, "Impact of nonlinear loads on anisotropic transformers," IEEE Trans. Power Delivery, vol. 6, no. 4, pp. 1781-1788, 1991

[76] E.F. Fuchs, M.A.S. Masoum, D.J. Roesler, "Large signal nonlinear model of anisotropic transformers for nonsinusoidal operation. I. $\lambda$-i characteristics," IEEE Trans. Power Delivery, vol. 6, no. 1, pp. 1874-1886, 1991

[77] R. de la Rosa, J. Carrillo, J. Dominguez, M. Perez, F. Moreno, E. Schtulmann, J.A. Cerrillo, C. Jimenez, "Reclosing principle application on the low voltage side of distribution transformers," IEEE Trans. Power Delivery, vol. 6, no. 4, pp. 1899-190, 1991

[78] A. Basak, C.H. Yu, "Analysis of magnetic fields in transformer cores using personal computers," COMPEL, vol. 11, no. 1, pp. 121-124, 1992

[79] V. Darley, "The practical application of fem techniques in transformer design \& development," COMPEL, vol. 11, no. 1, pp. 125-128, 1992

[80] A.G. Kladas, J.A. Tegopoulos " 3 d Finite element modelling of electromagnets and transformers by using a particular scalar potential technique," COMPEL, vol. 11, no. 1, pp. 129-132, 1992

[81] A.I. Lurie, V.P. Zenova, A.N. Panibratetz, "Tangent forces in transformer windings at short-circuit," COMPEL, vol. 11, no. 1, pp. 133-136,1992

[82] Z. Valkovic, "Some aspects of additional losses in step-lap joints of transformer core," COMPEL, vol. 11, no. 1, pp. 137-140, 1992.

[83] J. Turowskl, M. Kope\&cacute, M. Turowski, “3-D Computation and reduction of stray losses in transformer tanks with combined cu \& fe screens," COMPEL, vol. 11, no. 1, pp. 141-144, 1992.

[84] D. Thompson, Q. Wang, "Transformer winding leakage field effects and their calculation," COMPEL, vol. 11, no. 1, pp. 145-148, 1992.

[85] E. Napieralska Juszczak, "The fem analysis of nonsymetrical short circuit forces and fields in the window of convertor transformer," COMPEL, vol. 11, no. 1, pp. 213-216, 1992.

[86] X. Guo, H. A. Maier, K. Feser, “A new inrush detection method for transformer differential protection," Electrical Engineering, vol. 76, no. 1, pp. 83-91, 1992

[87] A. Fernandes-Costa, Manuel Vaz-Guedes, "Prevision of the Thermal Behavior of Dry-Type Cast Resin Transformers," Electric Power Components and Systems, vol. 20, no. 3, pp. 261-272, 1992

[88] L. G. Dias, M. E. El-Hawary, "Effect of Loads Fed by Fixed Tap Transformers on Conventional OPF Solutions," Electric Power Components and Systems, vol. 20, no. 5, pp. 505-512, 1992

[89] C. L. Cheng, C. E. Lin, C. L. Huang, J. C. Yeh, "A simple model for transformer inrush current calculation and harmonic analysis," Electric Power Systems Research, vol. 23, no. 3, pp. 153-163, 1992

[90] S. C. Gupta, B. P. Singh, "Determination of the impulse voltage distribution in windings of large power transformers," Electric Power Systems Research, vol. 25, no. 3, pp. 186-189, 1992

[91] S. H. Lin, "Prediction of the drying rate of transformer insulation during the dry cycle," Electric Power Systems Research, vol. 23, no. 3, pp. 227-231, 1992

[92] E. Arri, F. Mocci, M. Tosi, "Novel criteria for overload management in power transformers," European Transactions on Electrical Power, vol. 2, no. 2, pp. 77-82, 1992

[93] L. Scheltinga, P. T. M. Vaessen, "Digital measurement system for high-voltage impulse tests on transformers," European Transactions on Electrical Power, vol. 2, no. 2, pp. 111-116, 1992

[94] T. H. Janisch, G. Buchgraber, "Three-dimensional calculation of linear magnetic fields of not axisymmetrical winding arrangements in transformers," European Transactions on Electrical Power, vol. 2, no. 5, pp. 291-294, 1992

[95] J.N. Wrubel, "Monitoring program protects transformers from geomagnetic effects," IEEE Computer Applications in Power Magazine, vol. 5, no. 1, pp. 10-14, 1992

[96] M.T. Bishop, C. Gilker, "Portable harmonics meter evaluates transformer heating," IEEE Computer Applications in Power Magazine, vol. 5, no. 4, pp. 41-44, 1992

[97] E.R. Detjen, K.R. Shah, "Grounding transformer applications and associated protection schemes," IEEE Transactions on Industry Applications, vol. 28, no. 4, pp. 788-796, 1992

[98] K. Funaki, M. Iwakuma, S. Satoh, M. Hiramatsu, M. Takeo, 
K. Yamafuji, S. Nonaka, M. Hoshino, M. Simada, E. S. Yoneda, T. Sasaki, T. Fujioka, T. Kumano, E. Suzuki, "Development of a large-capacity superconducting cable for 1000 kVA-class power transformers," IEEE Trans. Magn., vol. 28, no. 1 , pp. 394-397, 1992

[99] N.I. Doinikov, A.S. Druzhinin, Y.M. Krivchenkov, V. A. Krylov, V. G. Kuchinsky, B.A. Larionov, G.M. Makeev, A.S. Simakov, V.F. Soikin, Y.V. Spirchenko, A. G.Panin, “900 MJ toroidal transformer-type inductive energy storage," IEEE Trans. Magn., vol. 28, no. 1, pp. 414-417, 1992

[100] N. Okada, H. Kamijo, T. Ishigohka, M. Yamamoto, "Fabrication and test of superconducting air-core autotransformer," IEEE Trans. Magn., vol. 28, no. 1, pp. 430-433, 1992

[101] T. Renyuan, Y. Junyou, L. Feng, L. Yongping, "Solutions of three-dimensional multiply connected and open boundary problems by BEM in three-phase combination transformers," IEEE Trans. Magn., vol. 28, no. 2, pp. 1340-1343, 1992

[102] K. Zakrzewski, M. Lukaniszyn, "Three-dimensional model of one- and three-phase transformer for leakage field calculation," IEEE Trans. Magn., vol. 28, no. 2, pp. 1344-1347, 1992

[103] S. Holland, G.P. O'Connell, L. Haydock, "Calculating stray losses in power transformers using surface impedance with finite elements," IEEE Trans. Magn., vol. 28, no. 2, pp. $1355-1358,1992$

[104] C.M. Arturi,"Force calculation in transformer windings under unbalanced MMFs by a non-linear finite element code," IEEE Trans. Magn., vol. 28, no. 2, pp. 1363-1366, 1992

[105] N. Guangzheng, X. Xiaoming, C. Weiying, L. Gangru, J. Baidun, F. Zhenghu, L. Xianghua, X. Jitai, "FEM analysis of 3 -D transformer leakage field and eddy current loss in the windings," IEEE Trans. Magn., vol. 28, no. 2, pp. 1382-1385, 1992

[106] T. Renyuan, L. Yan, L. Dake, T. Lijian, "Numerical calculation of 3D eddy current field and short circuit electromagnetic force in large transformers," IEEE Trans. Magn., vol. 28, no. 2, pp. 1418-1421, 1992

[107] Y. Jiansheng, C. Naizhong, L. Wenping, C. Xiang, S. Hanguang, "The calculation of short-circuit reactance of transformers by complementary variational principles," IEEE Trans. Magn., vol. 28, no. 2, pp. 1422-1425, 1992

[108] M. Mino, T. Yachi, A. Tago, K. Yanagisawa, K. Sakakibara, "A new planar microtransformer for use in micro-switching converters," IEEE Trans. Magn., vol. 28, no. 4, pp. 1969-1973, 1992

[109] T. Nakata, N. Takahashi, K. Fujiwara, M. Nakano, M. Nagao, "A low loss transformer using a rotating magnetic field," IEEE Trans. Magn., vol. 28, no. 5, pp. 2163-2165, 1992

[110] O. Ichinokura, K. Tajima, T. Jinzenji, "Study of push-pull parametric transformer," IEEE Trans. Magn., vol. 28, no. 5, pp. 2181-2183, 1992

[111] H. Yamaguchi, Y. Sato, T. Kataoka, "Loss characteristics of air-core superconducting transformer," IEEE Trans. Magn., vol. 28 , no. 5, pp. 2232-2234, 1992

[112] A.A. Arkadan, R.H. VanderHeiden, "Three-dimensional nonlinear finite element modeling of a voltage source excited transformer feeding a rectifier load," IEEE Trans. Magn., vol. 28 , no. 5, pp. 2265-2267, 1992
[113] Y. Kobayashi, S. Ishibashi, K. Shirakawa, J. Toriu, H. Matsuki, K. Murakami, K., "New type micro cloth-inductor and transformer with thin amorphous wires and multi-thin coils," IEEE Trans. Magn., vol. 28, no. 5, pp. 3012-3014, 1992

[114] H. Tsujimoto, T. Wada, K. Shirae, "Influence of the control signal input in pinhole device [thin-film transformer]," IEEE Trans. Magn., vol. 28, no. 5, pp. 3018-320, 1992

[115] E. So, "The application of the current-comparator technique in instrumentation and measurement equipment for the calibration of non-conventional instrument transformers with non-standard rated outputs," IEEE Trans. Power Delivery, vol. 7, no. 1, pp. 46-52, 1992

[116] J. Bak-Jenson, B. Bak-Jenson, S.D. Mikkelsen, C.G. Jensen, "Parametric identification in potential transformer modelling,", IEEE Trans. Power Delivery, vol. 7, no. 1, pp. 70-76, 1992

[117] T.S. Sidhu, M.S. Sachdev, H.C. Wood, M. Nagpal, "Design, implementation and testing of a microprocessor-based high-speed relay for detecting transformer winding faults," IEEE Trans. Power Delivery, vol. 7, no. 1, pp. 108-117, 1992

[118] J.R. Lucas, P.G. McLaren, W.W.L. Keerthipala, R.P. Jayasinghe, "Improved simulation models for current and voltage transformers in relay studies," IEEE Trans. Power Delivery, vol. 7, no. 1, pp. 152-159, 1992

[119] Y. Liu, S.A. Sebo, R. Caldecott, D. G. Kasten, S. E. Wright, "Power transformer resonance-measurements and prediction," IEEE Trans. Power Delivery, vol. 7, no. 1, pp. 245-253, 1992

[120] F. de Leon, A. Semlyen, "Reduced order model for transformer transients," IEEE Trans. Power Delivery, vol. 7, no. 1, pp. 361-369, 1992

[121] K. Kano, Y. Kawabuchi, K. Uchida, T. Yashiro, T. Shibata, "Line trapped charge discharging characteristic of gas insulated magnetic voltage transformer," IEEE Trans. Power Delivery, vol. 7, no. 1, pp. 370-375, 1992

[122] F. de Leon, A. Semlyen, "Efficient calculation of elementary parameters of transformers," IEEE Trans. Power Delivery, vol. 7, no. 1, pp. 376-383, 1992

[123] P.T.M. Vaessen, E. Hanique, "A new frequency response analysis method for power transformers," IEEE Trans. Power Delivery, vol. 7, no. 1, pp. 384-391, 1992

[124] W.J. McNutt, "Insulation thermal life considerations for transformer loading guides," IEEE Trans. Power Delivery, vol. 7 , no. 1, pp. 392-401, 1992

[125] J. Aubin, Y. Langhame, "Effect of oil viscosity on transformer loading capability at low ambient temperatures," IEEE Trans. Power Delivery, vol. 7, no. 2, pp. 516-524, 1992

[126] A.A. Girgis, D.G. Hart, W.B. Chang, W.B. "An adaptive scheme for digital protection of power transformers," IEEE Trans. Power Delivery, vol. 7, no. 2, pp. 546-553, 1992

[127] M.J. Gorman, J.J. Grainger, "Transformer modelling for distribution system studies. I. Linear modelling basics," IEEE Trans. Power Delivery, vol. 7, no. 2, pp. 567-574, 1992

[128] M.J. Gorman, J.J. Grainger, "Transformer modelling for distribution system studies. II. Addition of models to $\mathrm{Y}_{\mathrm{BUS}}$ and $\mathrm{Z}_{\mathrm{BUS}}$," IEEE Trans. Power Delivery, vol. 7, no. 2, pp. $575-580,1992$ 
[129] J.F. Baranowski, P.J. Hopkinson, “An alternative evaluation of distribution transformers to achieve the lowest TOC," IEEE Trans. Power Delivery, vol. 7, no. 2, pp. 614-619, 1992

[130] R.C. Degeneff, M.R. Gutierrez, P.J. McKenny, “A method for constructing reduced order transformer models for system studies from detailed lumped parameter models," IEEE Trans. Power Delivery, vol. 7, no. 2, pp. 649-655, 1992

[131] R.S. Girgis, C.-D Ko, "Calculation techniques and results of effects of GIC currents as applied to large power transformers," IEEE Trans. Power Delivery, vol. 7, no. 2, pp. 699-705, 1992

[132] S. Kobayashi, A. Horide, I. Takagi, M. Higaki, G. Takahashi, E. Mori, T. Yamagiwa, "Development and field test evaluation of optical current and voltage transformers for gas insulated switchgear," IEEE Trans. Power Delivery, vol. 7, no. 2, pp. $815-821,1992$

[133] H. Muramoto, T. Yamazaki, T. Oshi, "Development and application of the $275 \mathrm{kV} 300$ MVA separate-cooling, sheet-winding gas-insulated transformer," IEEE Trans. Power Delivery, vol. 7, no. 2, pp. 888-894, 1992

[134] L.W. Pierce, "An investigation of the temperature distribution in cast-resin transformer windings," IEEE Trans. Power Delivery, vol. 7, no. 2, pp. 920-926, 1992

[135] J.R. Stewart, L.J. Oppel, G.C. Thomann, T.F. Donazio, R.B. Rebbrapragada, "Transformer winding selection associated with reconfiguration of existing double circuit line to six-phase operation," IEEE Trans. Power Delivery, vol. 7, no. 2, pp. 979-985, 1992

[136] A.G. Levit, O.N. Grechko, N.P.Shchipunova, “Allowance for insulation ageing in the new concept of accelerated life tests of high-voltage power transformers," IEEE Trans. Power Delivery, vol. 7, no. 3, pp. 1089-1096, 1992

[137] L.M. Popovic, "Analytical expressions for estimating resonant frequencies of machine and transformer windings," IEEE Trans. Power Delivery, vol. 7, no. 3, pp. 1338-1346, 1992

[138] L.W. Pierce, "An investigation of the thermal performance of an oil filled transformer winding," IEEE Trans. Power Delivery, vol. 7, no. 3, pp. 1347-1358, 1992

[139] K. Hoyong, K. Yunseok, J. Kyung-Hee, "Algorithm of transferring the load of the faulted substation transformer using the best-first search method," IEEE Trans. Power Delivery, vol. 7, no. 3, pp. 1434-1442, 1992

[140] A. Medina, J. Arrillaga, "Generalised modelling of power transformers in the harmonic domain," IEEE Trans. Power Delivery, vol. 7, no. 3, pp. 1458-1465, 1992

[141] G.L. Goedde, R.C. Dugan, L.D. Rowe, "Full scale lightning surge tests of distribution transformers and secondary systems," IEEE Trans. Power Delivery, vol. 7, no. 3, pp. 1592-1600, 1992

[142] T.S. Sidhu, M.S. Sachdev, "Online identification of magnetizing inrush and internal faults in three-phase transformers," IEEE Trans. Power Delivery, vol. 7, no. 4, pp. 1885-1891, 1992

[143] P. Liu, O.P. Malik, D. Chen, G.S. Hope, Y. Guo, "Improved operation of differential protection of power transformers for internal faults," IEEE Trans. Power Delivery, vol. 7, no. 4, pp.
1912-1919, 1992

[144] M. Kezunovic, L. Kojovic, V. Skendzic, "Digital models of coupling capacitor voltage transformers for protective relay transient studies," IEEE Trans. Power Delivery, vol. 7, no. 4, pp. 1927-1935, 1992

[145] K.C. Schneider, R.F. Hoad, "Initial transformer sizing for single-phase residential load," IEEE Trans. Power Delivery, vol. 7, no. 4, pp. 2074-2081, 1992

[146] T. Nakata, N. Takahashi, K. Fujiwara, M. Nakano, M. Seno, "Magnetic characteristics of magnetic materials at very low temperature and their application to transformers," Journal of Magnetism and Magnetic Materials, vol. 112, no. 1-3, pp. 174-176, 1992

[147] E. Leśniewska, I. Borowska-Banaś, “Application of the finite element method for optimization of the current transformer insulation system," Electrical Engineering, vol. 76, no. 3, pp. 235-242, 1993

[148] Dj. Kalić, Z. Radaković, Z. Lazarević, R. Radosavljević, “On the determination of characteristic temperatures in power oil transformers during transient states," Electrical Engineering, vol. 76 , no. 6 , pp. 457-468, 1993

[149] S. Jayaram, H. S. Chandrasekharaiah, "Influence of secondary winding terminal conditions on impulse distribution in transformer windings," Electric Power Components and Systems, vol. 21, no. 2, pp. 183-198, 1993

[150] F. E. Abdel-Kader, A. A. Mohamed, "Welding transformer control by the electronic control of leakage flux," Electric Power Components and Systems, vol. 21, no. 3, pp. 217-227, 1993

[151] J. Kowalski, K. Pylak, "Polyoptimization problem in power core-type transformer design," Electric Power Components and Systems, vol. 21, no. 4, pp. 493-506, 1993

[152] S.S. Ahmed, M. Tawrit, "Analysis of the faults involving adjacent conductors of a six-phase transmission line together with a modelling of the phase conversion transformer," Electric Power Systems Research, vol. 27, no. 2, pp. 99-105, 1993

[153] A.M. Basha, K.Anantha Raman, "PC based IIR filter algorithm for power transformer relaying," Electric Power Systems Research, vol. 28, no. 2, pp. 123-127, 1993

[154] M. Yamamoto, N. Okada, T. Ishigohka, I. Ishii, "A study on a coreless superconducting transformer," IEEE Transactions on Applied Superconductivity, vol. 3, no. 1, pp. 889-892, 1993

[155] C.M. Muirhead, F. Wellhofer, T.W. Button, A.N. McN., "Assessment of thick film YBCO for flux transformer and magnetic screening applications," IEEE Transactions on Applied Superconductivity, vol. 3, no. 1, pp. 1695-1697, 1993

[156] J. Lin, T.W. Huang, J.J. Wang,H .B.Lu,S .L.Tu,S.J .Yang and S.E.Hsu, "YBCO DC SQUID on MgO bicrystal substrate with flux transformer," IEEE Transactions on Applied Superconductivity, vol. 3, no. 1, pp. 2438-2441, 1993

[157] B. Roas, G. Friedl, L. Bar, "Preparation and characterization of planar $\mathrm{YBa}_{2} \mathrm{Cu}_{3} \mathrm{O}_{\mathrm{x}}$ flux transformers," IEEE Transactions on Applied Superconductivity, vol. 3, no. 1, pp. 2442-2444, 1993

[158] M.S. Rauls, D.W. Novotny, D.M. Divan, "Design considera- 
tions for high-frequency coaxial winding power transformers," IEEE Transactions on Industry Applications, vol. 29, no. 2, pp. 375-381, 1993

[159] K. Inagaki, T. Furuhashi, A. Ishiguro, M. Ishida, S. Okuma, "A new PWM control method for AC to DC converters with high-frequency transformer isolation," IEEE Transactions on Industry Applications, vol. 29, no. 3, pp. 486-492, 1993

[160] L.W. Pierce, "Specifying and loading cast-resin transformers," IEEE Transactions on Industry Applications, vol. 29, no. 3, pp. 590-599, 1993

[161] R. K. Kump, "Why should the steel industry do anything with their PCB transformers?" IEEE Transactions on Industry Applications, vol. 29, no. 5, pp. 841-845, 1993

[162] Z. Azzouz, A. Foggia, L. Pierrat, G. Meunier, "3D finite element computation of the high frequency parameters of power transformer windings," IEEE Trans. Magn., vol. 29, no. 2, pp. 1407-1410, 1993

[163] C. Guerin, G. Tanneau, G. Meunier, "3D eddy current losses calculation in transformer tanks using the finite element method," IEEE Trans. Magn., vol. 29, no. 2, pp. 1419-1422, 1993

[164] C.H. Yu, A. Basak, "Optimum design of transformer cores by analysing flux and iron loss with the aid of a novel software," IEEE Trans. Magn., vol. 29, no. 2, pp. 1446-1449, 1993

[165] C.M. Arturi, "Electromagnetic force calculations on a 3-phase autotransformer under time-varying fault by a $3 \mathrm{D}$ non-linear finite element code," IEEE Trans. Magn., vol. 29, no. 2, pp. 2010-2013, 1993

[166] K. Yamaguchi, S. Ohnuma, T. Imagawa, "Characteristics of a thin film microtransformer with circular spiral coils," IEEE Trans. Magn., vol. 29, no. 5, pp. 2232-2237, 1993

[167] H. Kurata, K. Shirakawa, O. Nakazima, K. Murakami, "Study of thin film micro transformer with high operating frequency and coupling coefficient," IEEE Trans. Magn., vol. 29, no. 6, pp. 3204-3206, 1993

[168] K. Yamaguchi, E. Sugawara, O. Nakajima, H. Matsuki, K. Murakami, "Load characteristics of a spiral coil type thin film microtransformer," IEEE Trans. Magn., vol. 29, no. 6, pp. 3207-3209, 1993

[169] M.E.A. Hijazi, A. Basak, "Analysis of integral method for fault detection in transformers," IEEE Trans. Magn., vol. 29, no. 6 , pp. $3213-3215,1993$

[170] M. Kimura, J. Hayasaki, "Characteristics and simulations of the planar multi-layer spiral coil and the miniature opto-electric transformer," IEEE Trans. Magn., vol. 29, no. 6, pp. 3216-3218, 1993

[171] S. Hornfeldt, O. Albertsson, D. Bonmann, F. Konig, "Power transformer with superconducting windings," IEEE Trans. Magn., vol. 29, no. 6, pp. 3556-3558, 1993

[172] T. Kataoka, H. Yamaguchi, Y. Sato, S. Hayashi, H. Morimoto, "Volt-ampere rating of air-core superconducting power transformers," IEEE Trans. Magn., vol. 29, no. 6, pp. 3592-3594, 1993

[173] Y. Liu, S.A. Sebo, R. Caldecott, D.G. Kasten, S.E. Wright, "Modeling of converter transformers using frequency domain terminal impedance measurements," IEEE Trans. Power De- livery, vol. 8, no. 1, pp. 66-72, 1993

[174] V. Woivre, J.P. Arthaud, A. Ahmad, N. Burais, "Transient overvoltage study and model for shell-type power transformers," IEEE Trans. Power Delivery, vol. 8, no. 1, pp. 212-222, 1993

[175] C.E. Lin, J.M. Ling, C.L. Huang, "An expert system for transformer fault diagnosis using dissolved gas analysis," IEEE Trans. Power Delivery, vol. 8, no. 1, pp. 231-238, 1993.

[176] D. Pavlik, D.C. Johnson, R.S. Girgis, "Calculation and reduction of stray and eddy losses in core-form transformers using a highly accurate finite element modelling technique," IEEE Trans. Power Delivery, vol. 8, no. 1, pp. 239-245, 1993

[177] C.E. Lin, C.L. Cheng, C.L. Huang, J.C. Yeh, "Investigation of magnetizing inrush current in transformers. I. Numerical simulation," IEEE Trans. Power Delivery, vol. 8, no. 1, pp. 246-254, 1993

[178] C.E. Lin, C.L. Cheng, C.L. Huang, J.C. Yeh, "Investigation of magnetizing inrush current in transformers. II. Harmonic analysis," IEEE Trans. Power Delivery, vol. 8, no. 1, pp. 255-263, 1993

[179] A. Kudo, T. Nishitani, T. Yoshikawa, C.T. Wan, "Development of $275 \mathrm{kV}$ gas cooled type gas-insulated power transformer," IEEE Trans. Power Delivery, vol. 8, no. 1, pp. 264-270, 1993

[180]F. de Leon, A. Semlyen, "Time domain modeling of eddy current effects for transformer transients," IEEE Trans. Power Delivery, vol. 8, no. 1, pp. 271-280, 1993

[181] S. Lu, Y. Liu, J. De La Ree, "Harmonics generated from a DC biased transformer," IEEE Trans. Power Delivery, vol. 8, no. 2, pp. 725-731, 1993

[182] P.M. Miljanic, E. So, “An improved current-comparator-based 1000-A transconductance amplifier for the in-situ calibration of transformer loss measuring systems," IEEE Trans. Power Delivery, vol. 8, no. 3, pp. 861-865, 1993

[183] Y. Yamagata, T. Oshi, H. Katsukawa, S. Kato, Y. Sakurai, "Development of optical current transformers and application to fault location systems for substations," IEEE Trans. Power Delivery, vol. 8, no. 3, pp. 866-873, 1993

[184] K.J. Cornick, A.M. Kunji, "Nanosecond switching transients recorded in a mining transformer installation," IEEE Trans. Power Delivery, vol. 8, no. 3, pp. 1130-1137, 1993

[185] S. Lu, Y. Liu, "FEM analysis of DC saturation to assess transformer susceptibility to geomagnetically induced currents," IEEE Trans. Power Delivery, vol. 8, no. 3, pp. 1367-1376, 1993

[186] A.P.S. Meliopoulos, F. Zhang, S. Zelingher, "Transmission level instrument transformers and transient event recorders characterization for harmonic measurements," IEEE Trans. Power Delivery, vol. 8, no. 3, pp. 1507-1517, 1993

[187] L. Johansson, B. Magnuson, P. Riffon, "Loading capability of HVDC transformer bushings with restricted oil circulation for use in HVDC valve halls," IEEE Trans. Power Delivery, vol. 8, no. 3, pp. 1607-1614, 1993

[188] Morched, L. Marti, J. Ottevangers, "A high frequency transformer model for the EMTP," IEEE Trans. Power Delivery, 
vol. 8, no. 3, pp. 1615-1626, 1993

[189] A.O. Soysal, A. Semlyen, "Practical transfer function estimation and its application to wide frequency range representation of transformers," IEEE Trans. Power Delivery, vol. 8, no. 3, pp. 1627-1637, 1993

[190] K. Tomsovic, M. Tapper, T. Ingvarsson, “A fuzzy information approach to integrating different transformer diagnostic methods," IEEE Trans. Power Delivery, vol. 8, no. 3, pp. 1638-1646, 1993

[191] R.A. Walling, K.D. Barker, T.M. Compton, L.E. Zimmerman, "Ferroresonant overvoltages in grounded wye-wye padmount transformers with low-loss silicon steel cores," IEEE Trans. Power Delivery, vol. 8, no. 3, pp. 1647-1660, 1993

[192] K. Kurosawa, S. Yoshida, E. Mori, G.Takahashi, S. Saito, "Development of an optical instrument transformer for DC voltage measurement," IEEE Trans. Power Delivery, vol. 8, no. 4 , pp. 1721-1726, 1993

[193] D.L. Bassett, "Control of tap change under load transformers through the use of programmable logic controllers," IEEE Trans. Power Delivery, vol. 8, no. 4, pp. 1759-1765, 1993

[194] O. Soysal, "A method for wide frequency range modeling of power transformers and rotating machines," IEEE Trans. Power Delivery, vol. 8, no. 4, pp. 1802-1810, 1993

[195] D. Dolinar, J. Pihler, B. Grcar, "Dynamic model of a three-phase power transformer," IEEE Trans. Power Delivery, vol. 8, no. 4, pp. 1811-1819, 1993

[196] S.D. Foss, L. Savio, "Mathematical and experimental analysis of the field drying of power transformer insulation," IEEE Trans. Power Delivery, vol. 8, no. 4, pp. 1820-1828, 1993

[197] A. Semlyen, F. de Leon, "Computation of electromagnetic transients using dual or multiple time steps," IEEE Trans. Power Syst., vol. 8, no. 3, pp. 1274-1281, 1993

[198] N. D. Hatziargyriou, J. M. Prousalidis, B. C. Papadias, "Generalised transformer model based on the analysis of its magnetic core circuit," IET Gener.Transm. Distrib., vol. 140, no. 4 , pp. 269 - 278, 1993

[199]K. Zakrzewski, B. Tomczuk, "3-D Calculation of zero-component flux in three-phase three-column transformer," COMPEL, vol. 13, no. 1, pp. 93-96, 1994

[200] K. Komeza, S. Wiak, "Electromagnetic field calculation of a leakage transformer by means of finite element method with hermitian elements," COMPEL, vol. 13, no. 1, pp. 97-100, 1994

[201] A. Rezic, Z. Valkovic, “Additional losses in overlapping area of transformer core," COMPEL, vol. 13, no. 1, pp. 101-104, 1994

[202] J.Turowski, M. Kopec, "3-D Hybrid analytically-numerical computation of tank losses in 3-phase power transformers," COMPEL, vol. 13, no. 1, pp. 105-108, 1994

[203] C. Yongbin, Y. Junyou, Y. Hainian, T. Renyuan, "Computation of $3 \mathrm{~d}$ eddy current fields and losses due to leads in a large power transformer," COMPEL, vol. 13, no. 1, pp. 109-112, 1994

[204] M.R. Harris, R.L. Stoll, J.K. Sykulski, "Generic field problems in design studies of high temperature superconducting transformers," COMPEL, vol. 13, no. 1, pp. 167-170, 1994

[205] J. Stenzel, T. Weber, "Model representing the nonlinear behaviour of three-phase transformers," Electrical Engineering, vol. 77, no. 2, pp. 143-150, 1994

[206] H. Yamaguchi, Y. Sato, T. Kataoka, "Characteristics analysis of superconducting power transformer without iron core," Electrical Engineering in Japan, vol. 114, no. 8, pp. 80-92, 1994

[207] W. Fushuan, S. Wennan, “A modified three-phase model of transformers with delta-connected windings," Electric Power Components and Systems, vol. 22, no. 1, pp. 53-59, 1994.

[208] J.C. Yeh, C.E. Lin, C.L. Huang, C.L. Cheng, "Calculation and harmonic analysis of transient inrush currents in three-phase transformers," Electric Power Systems Research, vol. 30, no. 2, pp. 93-102, 1994

[209] T.T. Nguyen, "Developments in computational methods for transformer cyclic loading evaluations," Electric Power Systems Research, vol. 31, no. 3, pp. 175-183, 1994

[210] I. Bojna, P. Jahn, "The rms method and its application to the evaluation of errors of instrument transformers at non-sinusoidal waveforms," European Transactions on Electrical Power, vol. 4, no. 2, pp. 127-133, 1994

[211] C. M. Arturi, "Model of a highly saturated three-phase autotransformer with tertiary winding and five-limb core and analysis of a time-varying short-circuit transient," European Transactions on Electrical Power, vol. 4, no. 6, pp. 513-524, 1994

[212] F.I. Mopsik, "Stability of a numerical Laplace transform for dielectric measurements," IEEE Transactions on Dielectrics and Electrical Insulation, vol. 1, no. 1, pp. 3-8, 1994

[213] S.M. Mahajan, T.S. Sudarshan, "Measurement of the space charge field in transformer oil using its Kerr effect," IEEE Transactions on Dielectrics and Electrical Insulation, vol. 1, no. 1, pp. 63-70, 1994

[214] M. Zahn, "Transform relationship between Kerr-effect optical phase shift and nonuniform electric field distributions," IEEE Transactions on Dielectrics and Electrical Insulation, vol. 1, no. 4, pp. 235-246, 1994

[215] G. Touchard, P.O. Grimaud, H. Romat, O. Moreau, "Flow electrification in power transformers. Explanation of the wall-current measurements," IEEE Transactions on Dielectrics and Electrical Insulation, vol. 1, no. 4, pp. 728-733, 1994

[216] A. Sierota, J. Rungis, "Electrostatic charging in transformer oils. Testing and assessment," IEEE Transactions on Dielectrics and Electrical Insulation, vol. 1, no. 5, pp. 840-870, 1994

[217] L.W. Pierce, "Predicting liquid filled transformer loading capability," IEEE Transactions on Industry Applications, vol. 30, no. 1, pp. 170-178, 1994

[218] G.W. Massey, "Estimation methods for power system harmonic effects on power distribution transformers," IEEE Transactions on Industry Applications, vol. 30, no. 2, pp. 485-489, 1994

[219] R.D. Henderson, P.J. Rose, "Harmonics: the effects on power quality and transformers," IEEE Transactions on Industry 
Applications, vol. 30, no. 3, pp. 528-532, 1994

[220] L.W. Pierce, "Thermal considerations in specifying dry-type transformers," IEEE Transactions on Industry Applications, vol. 30, no. 4, pp. 1090-1098, 1994

[221] J.F. Witte, F.P. DeCesaro, S.R. Mendis, "Damaging long-term overvoltages on industrial capacitor banks due to transformer energization inrush currents," IEEE Transactions on Industry Applications, vol. 30, no. 4, pp. 1107-1115, 1994

[222] F. Loffler, H. Pfutzner, T. Booth, C. Bengtsson, K. Gramm, "Influence of air gaps in stacked transformer cores consisting of several packages," IEEE Trans. Magn., vol. 30, no. 2, pp. 913-915, 1994

[223] T. Hoshino, I. Muta, "Load test on superconducting transformer and fault current limiting devices for electric power system," IEEE Trans. Magn., vol. 30, no. 2, pp. 2018-2021, 1994

[224] H. Pfutzner, C. Bengtsson, T. Booth, F. Loffler, K. Gramm, "Three-dimensional flux distributions in transformer cores as a function of package design," IEEE Trans. Magn., vol. 30, no. 5 , pp. 2713-2727, 1994

[225] B. Tomczuk, "Analysis of 3-D magnetic fields in high leakage reactance transformers," IEEE Trans. Magn., vol. 30, no. 5, pp. 2734-2738, 1994

[226] C. Xiang, L. Jianxin, X. Yucheng, H. Ronggui, Z. Guoqiang, Y. Chunping, "Design of insulated structure for load-ratio voltage power transformer by finite element method," IEEE Trans. Magn., vol. 30, no. 5, pp. 2944-2947, 1994

[227] L. Haydock, S.A. Holland, "Transient analysis of power transformers using magnetic and electric equivalent circuits," IEEE Trans. Magn., vol. 30, no. 5, pp. 2996-2999, 1994

[228] C. Yongbin, Y. Junyou, Y. Hainian, T. Renyuan, "Study on eddy current losses and shielding measures in large power transformers," IEEE Trans. Magn., vol. 30, no. 5, pp. 3068-3071, 1994

[229] S. Bouissou, F. Piriou, C. Kieny, G. Tanneau, "Numerical simulation of a power transformer using 3D finite element method coupled to circuit equation," IEEE Trans. Magn., vol. 30, no. 5, pp. 3224-3227, 1994

[230] N. Richard, N. Szylowicz, "Comparison between a permeance network model and a 2D finite element model for the inrush current computation in a three phase transformer," IEEE Trans. Magn., vol. 30, no. 5, pp. 3232-3235, 1994

[231] C. Reyne, H. Magnin, G. Berliat, C. Clerc, “A supervisor for the successive 3D computations of magnetic, mechanical and acoustic quantities in power oil inductors and transformers," IEEE Trans. Magn., vol. 30, no. 5, pp. 3292-3295, 1994

[232] A.G. Kladas, M.P. Papadopoulos, J.A.Tegopoulos, "Leakage flux and force calculation on power transformer windings under short-circuit: 2D and 3D models based on the theory of images and the finite element method compared to measurements," IEEE Trans. Magn., vol. 30, no. 5, pp. 3487-3490, 1994

[233] Y. Ohdachi, Y. Kawase, T. Tainaka, T. Yamaguchi, "Load characteristics analysis of coupling transformer using 3-D finite element method with edge elements," IEEE Trans. Magn., vol. 30, no. 5, pp. 3721-3724, 1994
[234] A. Basak, Chi-Hang Yu, G. Lloyd, "Efficient transformer design by computing core loss using a novel approach," IEEE Trans. Magn., vol. 30, no. 5, pp. 3725-3728, 1994

[235] A. Ahmad, P. Auriol, C. Kieny, "Shell-form power transformer modelling at high frequencies," IEEE Trans. Magn., vol. 30 , no. 5, pp. 3729-3732, 1994

[236] S. Hayano, Y. Midorikawa, Y. Saito, "Development of film transformer," IEEE Trans. Magn., vol. 30, no. 5, pp. 4758-4760, 1994

[237] T. Yanada, T. Matsuda, O. Ichinokura, T. Jinzenji, "Performance and noise attenuation mechanism of noise reduction transformer," IEEE Trans. Magn., vol. 30, no. 5, pp. 4860-4862, 1994

[238] Yu-Ting Huang, Chi-Jen Chen, Wen-Ben Shu, "Finite element analysis on characteristics of rotary transformers," IEEE Trans. Magn., vol. 30, no. 5, pp. 4866-4868, 1994

[239] M.A.S. Masoum, E.F. Fuchs, "Transformer magnetizing current and iron-core losses in harmonic power flow," IEEE Trans. Power Delivery, vol. 9, no. 1, pp. 10-20, 1994

[240] F. de Leon, A. Semlyen, "Complete transformer model for electromagnetic transients," IEEE Trans. Power Delivery, vol. 9 , no. 1, pp. 231-239, 1994

[241] J.A. Ebert, “Application considerations for variable volts per turn power transformers," IEEE Trans. Power Delivery, vol. 9 , no. 1 , pp. $240-248,1994$

[242] S. Ezure, Y. Imai, H. Sato, S. Yamada, K. Yamanaka, S. Saito, "Long-term reliability of amorphous alloy wound core distribution transformers," IEEE Trans. Power Delivery, vol. 9, no. 1 , pp. 249-256, 1994

[243] L.W. Pierce, "Hottest spot temperatures in ventilated dry type transformers," IEEE Trans. Power Delivery, vol. 9, no. 1, pp. 257-264, 1994

[244] L.B. Wagenaar, J.M. Schneider, J.A. Fleeman, "EHV transformer dielectric specification improvements," IEEE Trans. Power Delivery, vol. 9, no. 1, pp. 265-284, 1994

[245] M.A. Ibrahim, F.P. Stacom, "Phase angle regulating transformer protection," IEEE Trans. Power Delivery, vol. 9, no. 1, pp. 394-404, 1994

[246] M. Kezunovic, L. Kojovic, A. Abur, C.W. Fromen, D.R. Sevcik, F. Phillips, "Experimental evaluation of EMTP-based current transformer models for protective relay transient study," IEEE Trans. Power Delivery, vol. 9, no. 1, pp. 405-413, 1994

[247] P. Bastard, P. Bertrand, M. Meunier, "A transformer model for winding fault studies," IEEE Trans. Power Delivery, vol. 9 , no. 2, pp. 690-699, 1994

[248] A.J.F. Keri, Y.I. Musa, J.A. Halladay, "Insulation coordination for delta connected transformers," IEEE Trans. Power Delivery, vol. 9, no. 2, pp. 772-780, 1994

[249] R.A. Walling, R.K. Hartana, R.M. Reckard, M.P. Sampat, T.R. Balgie, "Performance of metal-oxide arresters exposed to ferroresonance in padmount transformers," IEEE Trans. Power Delivery, vol. 9, no. 2, pp. 788-795, 1994.

[250] F. de Leon, A. Semlyen, "Detailed modeling of eddy current effects for transformer transients," IEEE Trans. Power De- 
livery, vol. 9, no. 2, pp. 1143-1150, 1994

[251] B.C. Papadias, N.D. Hatziargyriou, J.A. Bakopoulos, J.M. Prousalidis, "Three phase transformer modelling for fast electromagnetic transient studies," IEEE Trans. Power Delivery, vol. 9, no. 2, pp. 1151-1159, 1994.

[252] L.W. Pierce, "Predicting hottest spot temperatures in ventilated dry type transformer windings," IEEE Trans. Power Delivery, vol. 9, no. 2, pp. 1160-1172, 1994.

[253] N. Takasu, T. Oshi, F. Miyawaki, S. Saito, Y. Fujiwara, “An experimental analysis of DC excitation of transformers by geomagnetically induced currents," IEEE Trans. Power Delivery, vol. 9, no. 3, pp. 1173-1182, 1994

[254] M.F. Lachman, "Field measurements of transformer single-phase exciting current as a diagnostic tool, and influence of load tap changers," IEEE Trans. Power Delivery, vol. 9, no. 3, pp. 1466-1475, 1994

[255] P. Matthiessen, K.P. Ellis, "Field experience with an on-line gas monitoring device for oil filled instrument transformers," IEEE Trans. Power Delivery, vol. 9, no. 3, pp. 1476-1479, 1994

[256] E. Takahashi, Y. Shirasaka, K. Okuyama, "Analysis of an anisotropic nonlinear electric field with a discussion of dielectric tests for converter transformers and smoothing reactors," IEEE Trans. Power Delivery, vol. 9, no. 3, pp. 1480-1486, 1994

[257] W. Xu, T.G. Martinich, J.H. Sawada, Y. Mansour, "Harmonics from SVC transformer saturation with direct current offset," IEEE Trans. Power Delivery, vol. 9, no. 3, pp. 1502-1509, 1994

[258] R. Malewski, M.A. Franchek, J.H. McWhirter, "Experimental validation of a computer model simulating an impulse voltage distribution in HV transformer windings," IEEE Trans. Power Delivery, vol. 9, no. 4, pp. 1789-1798, 1994

[259] Y. Nukaiyama, I. Takagi, H. Ishihara, A. Kudo, Y. Makino, N. Hosokawa, N. "Principal decomposition by-products generated at various abnormalities in gas-insulated transformers," IEEE Trans. Power Delivery, vol. 9, no. 4, pp. 1885-1891, 1994

[260] M. Vakilian, R.C. Degeneff, "A method for modeling nonlinear core characteristics of transformers during transients," IEEE Trans. Power Delivery, vol. 9, no. 4, pp. 1916-1925, 1994

[261] A. Medina, J. Arrillaga, “Analysis of transformer-generator interaction in the harmonic domain," IET Gener. Transm. Distrib., vol. 141, no. 1, pp. 38-46, 1994

[262] A. Semlyen, F. De Leon, "Eddy current add-on for frequency dependent representation of winding losses in transformer models used in computing electromagnetic transients," IET Gener. Transm. Distrib., vol. 141, no. 3, pp. 209-214, 1994

[263] B. Grcar, D. Dolinar, "Integrated digital power transformer protection," IET Gener. Transm. Distrib., vol. 141, no. 4, pp. 323-328, 1994

[264] C.K. Roy, J.R. Biswas, "Studies on impulse behaviour of a transformer winding with simulated faults by analogue modelling," IET Gener. Transm. Distrib., vol. 141, no. 5, pp. 401-412, 1994
[265] C.C. Wong, "Substation power-transformer-loading analysis and computer simulations of loadability under realistic operating conditions," IET Gener. Transm. Distrib., vol. 141, no. 5, pp. 413-421, 1994

[266] A.M. Emsley, G.C. Stevens, "Review of chemical indicators of degradation of cellulosic electrical paper insulation in oil-filled transformers," IET Science Measurement \& Technology, vol. 141, no. 5, pp. 324-334, 1994

[267] P.J. Betts, "Self-calibratable voltage transformer with part-per-million accuracy," IET Science Measurement \& Technology, vol. 141, no. 5, pp. 379-382, 1994

[268] R. Yacamini, H. Bronzeado, "Transformer inrush calculations using a coupled electromagnetic model," IET Science Measurement \& Technology, vol. 141, no. 6, pp. 491-498, 1994

[269] T. Booth, H. Pfützner, "Characteristics of transformer core materials for flux normal to the sheet plane," Journal of Magnetism and Magnetic Materials, vol. 133, no. 1-3, pp. 183-186, 1994

[270]E. Lesniewska, "The comparison of the methods used for estimation of current transformer metrological properties," COMPEL, vol. 14, no. 4, pp. 75-78, 1995

[271] M. Lukaniszyn, R. Unbehauen "The 3d analysis of the leakage field in a transformer with disk windings," COMPEL, vol. 14, no. 4, pp. 79-82, 1995

[272] J. E. Monson, "Design of a multi-channel rotary transformer for application to digital magnetic recording," COMPEL, vol. 14, no. 4, pp. 133-136, 1995

[273] A. Rezic, Z. Valkovic, "Calculation of flux distribution in transformer core taking hysteresis into account," COMPEL, vol. 14, no. 4, pp. 137-140, 1995.

[274] K. Zakrzewski, B. Tomczuk, "3D Magnetic field distribution of yoke flux in three-phase transformers without ferromagnetic tanks," COMPEL, vol. 14, no. 4, pp. 141-145, 1995

[275] M. Lukaniszyn, R. Unbehauen, "The 3-D calculations of the leakage magnetic field and the short-circuit reactance in a transformer with disk windings," Electrical Engineering, vol. 78, no. 3, pp. 151-157, 1995

[276] S. A. Soliman, M. M. El-Arini, A. M. Al-Kandari, M. E. El-Hawary, "Frequency domain parameter identification of harmonic potential transformer models using least square techniques," Electric Power Components and Systems, vol. 35, no. 1, pp. 45-49, 1995

[277] L. Lifeng, G. Zhongde, Y. Qixun, B. Zhongmin, “An expert system for designing the protection system of a power transformer," Electric Power Components and Systems, vol. 35, no. 1, pp. 59-64, 1995

[278] H. Yamaguchi, Y. Sato, T. Kataoka, "Comparison between superconducting and conventional power transformers considering auxiliary facilities," IEEE Transactions on Applied Superconductivity, vol. 5, no. 2, pp. 937-940, 1995

[279] T. Ise, Y. Marutani, Y. Murakami, E. Yoneda, R. Sugawara, "Characteristics of a $40 \mathrm{kVA}$ three phase superconducting transformer and its parallel operation with a conventional transformer," IEEE Transactions on Applied Superconductivity, vol. 5, no. 2, pp. 941-944, 1995 
[280] Y.A. Bashkirov, I.V. Yakimets, L.S. Fleishman, V.G. Narovlyanskii, "Application of superconducting shields in current-limiting and special-purpose transformers," IEEE Transactions on Applied Superconductivity, vol. 5, no. 2, pp. 1075-1078, 1995

[281] L. Peyraque, C. Boisdon, A. Beroual, F. Buret, "Static electrification and partial discharges induced by oil flow in power transformers," IEEE Transactions on Dielectrics and Electrical Insulation, vol. 2, no. 1, pp. 40-45, 1995

[282] F. Carraz, P. Rain, R. Tobazeon, "Particle-initiated breakdown in a quasi-uniform field in transformer oil," IEEE Transactions on Dielectrics and Electrical Insulation, vol. 2, no. 6 , pp. 1052-1063, 1995

[283] S. Itahashi, H. Mitsui, T. Sato, M. Sone, "State of water in hydrocarbon liquids and its effect on conductivity [transformer oil]," IEEE Transactions on Dielectrics and Electrical Insulation, vol. 2, no. 6, pp. 1117-1122, 1995.

[284] M.S. Rauls, D.W. Novotny, D.M. Divan, "Multiturn high-frequency coaxial winding power transformers," IEEE Transactions on Industry Applications, vol. 31, no. 1, pp. 112-118, 1995.

[285] G. Olivier, G.E. April, E. Ngandui, C. Guimaraes, ”Novel transformer connection to improve current sharing in high-current DC rectifiers," IEEE Transactions on Industry Applications, vol. 31, no. 1, pp. 127-133, 1995.

[286] M.M. Saied, "Effect of transformer sizes and neutral treatments on the electromagnetic transients in transformer substations," IEEE Transactions on Industry Applications, vol. 31, no. 2, pp. 384-391, 1995.

[287] K.W. Klontz, D.M. Divan, D.W. Novotny, "An actively cooled $120 \mathrm{~kW}$ coaxial winding transformer for fast charging electric vehicles," IEEE Transactions on Industry Applications, vol. 31, no. 6, pp. 1257-1263, 1995.

[288] J.J.L.M. van Vlerken, P.G. Blanken, "Lumped modeling of rotary transformers, heads and electronics for helical-scan recording," IEEE Trans. Magn., vol. 31, no. 2, pp. 1050-1055, 1995.

[289] C. Guerin, G. Tanneau, G. Meunier, P. Labie, T. Ngnegueu, M. Sacotte, "A shell element for computing 3D eddy currents-application to transformers," IEEE Trans. Magn., vol. 31, no. 3, pp. 1360-1363, 1995.

[290] Y. Midorikawa, I. Marinova, S. Hayano, Y. Saito, "Electromagnetic field analysis of film transformer," IEEE Trans. Magn., vol. 31, no. 3, pp. 1456-1459, 1995.

[291] E. Napieralska-Juszczak, R. Grzybowski, J.F. Brudny, "Modelling of losses due to eddy currents and hysteresis in converter transformer cores during failure," IEEE Trans. Magn., vol. 31, no. 3, pp. 1718-1721, 1995.

[292] C.M. Arturi, "3D FE analysis of the axial forces on the step-up transformer-windings with helicoidal LV," IEEE Trans. Magn., vol. 31, no. 3, pp. 2032-2035, 1995.

[293] R. Allcock, S. Holland, L. Haydock, "Calculation of zero phase sequence impedance for power transformers using numerical methods," IEEE Trans. Magn., vol. 31, no. 3, pp. 2048-2051, 1995.

[294] T. Tran-Quoc, L. Pierrat, “An efficient non linear transformer model and its application to ferroresonance study," IEEE
Trans. Magn., vol. 31, no. 3, pp. 2060-2063, 1995.

[295] T. Ngnegueu, M. Mailhot, A. Munar, M. Sacotte, "Zero phase sequence impedance and tank heating model for three phase three leg core type power transformers coupling magnetic field and electric circuit equations in a finite element software," IEEE Trans. Magn., vol. 31, no. 3, pp. 2068-2071, 1995.

[296] K. Hirata, Y. Mitsutake, Y. Ishihara, T. Todaka, "Numerical method for the performance of a separate-type transformer connected to battery charger," IEEE Trans. Magn., vol. 31, no. 3, pp. 2123-2126, 1995.

[297] T.O. Howard, K.H. Carpenter, "A numerical study of the coupling coefficients for pot core transformers," IEEE Trans. Magn., vol. 31, no. 3, pp. 2249-2253, 1995.

[298] I. Marinova, Y. Midorikawa, S. Hayano, Y. Saito, "Thin film transformer and its analysis by integral equation method," IEEE Trans. Magn., vol. 31, no. 4, pp. 2432-2437, 1995.

[299] B. Baodong, X. Dexin, C. Jiefan, O.A. Mohammed, “Optimal transposition design of transformer windings by Genetic Algorithms," IEEE Trans. Magn., vol. 31, no. 6, pp. 3572-3574, 1995.

[300] Th. Waeckerle, L.-L. Rouve, C. Talowski, "Study of anisotropic B-H models for transformer cores," IEEE Trans. Magn., vol. 31, no. 6, pp. 3991-3993, 1995.

[301] H. Yamaguchi, H. Moriomoto, Y. Sato, T. Kataoka, "Magnetic field analysis of air-core superconducting transformer," IEEE Trans. Magn., vol. 31, no. 6, pp. 4124-4126, 1995.

[302] H. Tsujimoto, O. Ieyasu, "High frequency transmission characteristic of co-planar film transformer fabricated on flexible polyamide film," IEEE Trans. Magn., vol. 31, no. 6, pp. 4232-4234, 1995.

[303] J.W. Lu, F.P. Dawson, S. Yamada, "Analysis of high frequency planar sandwich transformers for switching converters," IEEE Trans. Magn., vol. 31, no. 6, pp. 4235-4237, 1995.

[304] Y. Sakamoto, M. Natsusaka, M. Ohta, K. Murakami, O. Ichinokura, "A planar transformer utilizing a parametric oscillation," IEEE Trans. Magn., vol. 31, no. 6, pp. 4238-4240, 1995.

[305] Y. Midorikawa, S. Hayano, Y. Saito, "Improvement of the film transformer characteristics," IEEE Trans. Magn., vol. 31, no. 6 , pp. 4241-4243, 1995.

[306] A.A. Adly, "Determination of total transformer losses resulting from semirotating flux excitation," IEEE Trans. Magn., vol. 31, no. 6, pp. 4253-4255, 1995.

[307] R.K. Smith, “Tests show ability of vacuum circuit breaker to interrupt fast transient recovery voltage rates of rise of transformer secondary faults," IEEE Trans. Power Delivery, vol. 10, no. 1, pp. 266-273, 1995.

[308] G.C. Paap, A.A. Alkema, L. Van der Sluis, "Overvoltages in power transformers caused by no-load switching," IEEE Trans. Power Delivery, vol. 10, no. 1, pp. 301-307, 1995.

[309] J. Bak-Jensen, B. Bak-Jensen, S.D. Mikkelsen, "Detection of faults and ageing phenomena in transformers by transfer functions," IEEE Trans. Power Delivery, vol. 10, no. 1, pp. 308-314, 1995. 
[310] F. De Leon, A. Semlyen, "A simple representation of dynamic hysteresis losses in power transformers," IEEE Trans. Power Delivery, vol. 10, no. 1, pp. 315-321, 1995.

[311] R.A. Walling, R.K. Hartana, W.J. Ros, "Self-generated overvoltages due to open-phasing of ungrounded-wye delta transformer banks," IEEE Trans. Power Delivery, vol. 10, no. 1, pp. 526-533, 1995.

[312] J.A. Ebert, "Criteria for reliable dual voltage power transformers," IEEE Trans. Power Delivery, vol. 10, no. 2, pp. 845-852, 1995.

[313] C.W. Plummer, G.L. Goedde, E.L.Jr. Pettit, J.S.Godbee, M.G. Hennessey, "Reduction in distribution transformer failure rates and nuisance outages using improved lightning protection concepts," IEEE Trans. Power Delivery, vol. 10, no. 2, pp. 768-777, 1995.

[314] M. Gutierrez, R.C. Degeneff, P.J. McKenny, J.M. Schneider, "Linear, lumped parameter transformer model reduction technique," IEEE Trans. Power Delivery, vol. 10, no. 2, pp. 853-861, 1995.

[315] R.C. Degeneff, M.R. Gutierrez, M. Vakilian, "Nonlinear, lumped parameter transformer model reduction technique," IEEE Trans. Power Delivery, vol. 10, no. 2, pp. 862-868, 1995.

[316] R.S. Girgis, J.C. Baldwin, W.N. Kennedy, S. Monaco, S.R. Lindgren, R.D. Holm, R.E. Kothmann, "Design and performance improvements in power transformers using ribbon cable," IEEE Trans. Power Delivery, vol. 10, no. 2, pp. 869-879, 1995.

[317] K. Hiraishi, Y. Uwano, K. Shirakura, Y. Gotanda, M. Higaki, K. Endoo, M. Horikoshi, K. Mizuno, H. Hora, "Development and practical operation of perfluorocarbon immersed $275 \mathrm{kV}$ transformers with compressed $\mathrm{SF}_{6}$ gas insulation," IEEE Trans. Power Delivery, vol. 10, no. 2, pp. 880-888, 1995.

[318] R. Levi, S. Manifase, "Further studies of anomalous phenomena in dielectric-loss measurements-transformer bushings model," IEEE Trans. Power Delivery, vol. 10, no. 2, pp. 889-895, 1995.

[319] C.E. Lin, J.C. Yeh, C.L. Huang, C.L. Cheng, "Transient model and simulation in three-phase three-limb transformers," IEEE Trans. Power Delivery, vol. 10, no. 2, pp. 896-905, 1995.

[320] W.L.A. Neves, H.W. Dommel, W. Xu, "Practical distribution transformer models for harmonic studies," IEEE Trans. Power Delivery, vol. 10, no. 2, pp. 906-912, 1995.

[321] M.V. Thaden, S.P. Mehta, S.C. Tuli, R.L. Grubb, “Temperature rise tests on a forced-oil-air cooled (FOA) (OFAF) core-form transformer, including loading beyond nameplate," IEEE Trans. Power Delivery, vol. 10, no. 2, pp. 913-923, 1995.

[322] R.J. Galarza, J.H. Chow, R.C. Degeneff, "Transformer model reduction using time and frequency domain sensitivity techniques," IEEE Trans. Power Delivery, vol. 10, no. 1, pp. 1052-1059, 1995.

[323] S. Chimklai, J.R. Marti, "Simplified three-phase transformer model for electromagnetic transient studies," IEEE Trans. Power Delivery, vol. 10, no. 3, pp. 1316-1325, 1995.

[324] R. Jagadish, P.K. Poovamma, "Flow electrification characte- ristics of transformer oil by rotating electrode systems," IEEE Trans. Power Delivery, vol. 10, no. 3, pp. 1326-1331, 1995.

[325] L.H. Christensen, "Design, construction, and test of a passive optical prototype high voltage instrument transformer," IEEE Trans. Power Delivery, vol. 10, no. 3, pp. 1332-1337, 1995.

[326] W.L.A. Neves, H.W. Dommel, "Saturation curves of delta-connected transformers from measurements," IEEE Trans. Power Delivery, vol. 10, no. 3, pp. 1432-1437, 1995.

[327] J.J. Vithayathil, P.-E. Bjorklund, W. Mittlestadt, "DC systems with transformerless converters," IEEE Trans. Power Delivery, vol. 10, no. 3, pp. 1497-1504, 1995.

[328] H.J. Vermeulen, L.R. Dann, J. van Rooijen, "Equivalent circuit modelling of a capacitive voltage transformer for power system harmonic frequencies," IEEE Trans. Power Delivery, vol. 10, no. 4, pp. 1743-1749, 1995.

[329] C. Vailles, R. Malewski, Xuan Dai-Do, J. Aubin, "Measurements of dielectric stress in EHV power transformer insulation," IEEE Trans. Power Delivery, vol. 10, no. 4, pp. 1757-1763, 1995.

[330] A. Wiszniewski, B. Kasztenny, "A multi-criteria differential transformer relay based on fuzzy logic," IEEE Trans. Power Delivery, vol. 10, no. 4, pp. 1786-1792, 1995.

[331] M. Vakilian, R.C. Degeneff, M. Kupferschmid, "Computing the internal transient voltage response of a transformer with a nonlinear core using Gear's method. Part 1: Theory," IEEE Trans. Power Delivery, vol. 10, no. 4, pp. 1836-1842, 1995.

[332] W.R. Wieserman, G.L. Kusic, "Characterization of soft magnetic material METGLAS 2605S-3A for power applications and transformers," IEEE Trans. Power Delivery, vol. 10, no. 3, pp. 1842-1852, 1995.

[333] S. Nyati, M. Eitzmann, J. Kappenman, "Design issues for a single core transformer thyristor controlled phase-angle regulator," IEEE Trans. Power Delivery, vol. 10, no. 3, pp. 2013-2019, 1995.

[334] A.M. Gole, R. Verdolin, E. Kuffel, "Firing angle modulation for eliminating transformer DC currents in coupled AC-DC systems," IEEE Trans. Power Delivery, vol. 10, no. 3, pp. 2040-2047, 1995.

[335] T.H. Chen, H.-Y. Kuo, "Network modelling of traction substation transformers for studying unbalance effects," IET Gener.Transm. Distrib., vol. 142, no. 2, pp. 103-108, 1995.

[336] N. Li, K.W. Edwin, "Optimal phase angles of booster transformers in HV and EHV in power systems," IET Gener.Transm. Distrib., vol. 142, no. 2, pp. 185-189, 1995.

[337] T.T. Nguyen, "Constrained optimisation procedure for evaluating cyclic loading of power transformers," IET Gener.Transm. Distrib., vol. 142, no. 3, pp. 240-246, 1995.

[338] S. Mozaffari, S. Henschel, A.C. Soudack, "Chaotic ferroresonance in power transformers," IET Gener.Transm. Distrib., vol. 142 , no. 3 , pp. 247-250, 1995.

[339] R. Mihalic, P. Zunko, "Phase-shifting transformer with fixed phase between terminal voltage and voltage boost: tool for transient stability margin enhancement," IET Gener.Transm. Distrib., vol. 142, no. 3, pp. 257-262, 1995.

[340] P. Bastard, M. Meunier, H. Regal, "Neural network-based 
algorithm for power transformer differential relays," IET Gener.Transm. Distrib., vol. 142, no. 4, pp. 386-392, 1995.

[341] H. Yamaguchi, Y. Sate, T. Kataoka, "Conceptual design of air-core superconducting transformer for $500 \mathrm{kV}$ cable transmission system," IET Gener.Transm. Distrib., vol. 142, no. 5, pp. 487-493, 1995.

[342] Sheng-Nian Yeh, Jung-Fang Pern, "Calculating the current distribution in power transformer windings using finite element analysis with circuit constraints," IET Science Measurement \& Technology, vol. 142, no. 3, pp. 231-236, 1995.

[343] A. Dey, D.L. Jain, "Multidimensional Laplace transforms for solution of nonlinear equations," IET Science Measurement \& Technology, vol. 142, no. 3, pp. 267-268, 1995.

[344] H. Bronzeado, R. Yacamini, "Phenomenon of sympathetic interaction between transformers caused by inrush transients," IET Science Measurement \& Technology, vol. 142, no. 4, pp. 323-329, 1995.

[345] N. Foulon-Belkacemi, M. Goldman, A. Goldman, J. Amouroux, "Transformation of nodules into crystals on polymers submitted to corona discharges with streamers," IET Science Measurement \& Technology, vol. 142, no. 6, pp. 477-481, 1995.

[346] L. Tang, W. Zhirong, L. Huangzhang, N. Dexin, "Location of partial discharges in power transformers using computer-aided acoustic techniques," Canadian Journal of Electrical and Computer Enginering, vol. 20, No 2, pp. 67-72, 1996.

[347] J. W. Nims, R. E. Smith, A. A. El-Keib, "Application of a genetic algorithm to power transformer design," Electric Power Components and Systems, vol. 24, no. 6, pp. 669-680, 1996.

[348] P. S. Nagendra Rao, D. S. Ramakrishana, K. Parthasarathy, "An algorithm for relocation of distribution transformers," Electric Power Components and Systems, vol. 24, no. 7, pp. 721-732, 1996.

[349] A. Di Gerlando, I. Vistoli, "DC polarized current transformers for the measurement of harmonic noise," Electric Power Components and Systems, vol. 24, no. 7, pp. 757-77, 1996.

[350] D. Tousignant, L. Bolduc, A. Dutil, "A method for the indication of power transformer saturation," Electric Power Systems Research, vol. 37, no. 2, pp. 115-120, 1996.

[351] J. G. Vlachogiannis, J. Xypteras, A. G. Bakirtzis "Transformer model for application in load-how analysis," European Transactions on Electrical Power, vol. 6, no. 1, pp. 15-23, 1996.

[352] B. Culver, K. Fröhlich, L. Widenhorn "Prevention of tank rupture of faulted power transformers by generator circuit breakers," European Transactions on Electrical Power, vol. 6, no. 1 , pp. 39-45, 1996.

[353] M. Poljak, B. Bojanic, T. Hafner, J. Tomasevic "A new concept of combined transformers," European Transactions on Electrical Power, vol. 6, no. 4, pp. 253-258, 1996.

[354] M. Kozlowski, W. Pewca "Short-circuit performance of a stretched transformer winding with regard to its actual mechanical characteristics," European Transactions on Electrical Power, vol. 6, no. 4, pp. 259-265, 1996.

[355] J.L. Jr. Kirtley, W.H. Hagman, B.C. Lesieutre, M.J. Boyd,
E.P. Warren, H.P. Chou, R.D. Tabors, "Monitoring the health of power transformers," IEEE Computer Applications in Power Magazine, vol. 9, no. 1, pp. 18-23, 1996.

[356] M.M. Adibi, D.P. Milanicz, T.L. Volkmann, "Simulating transformer taps for remote cranking operations," IEEE Computer Applications in Power Magazine, vol. 9, no. 3, pp. 24-29, 1996.

[357] Y. You, E.F. Fuchs, D. Lin, P.R. Barnes, "Reactive power demand of transformers with DC bias," IEEE Ind. Appl. Mag., vol. 2, pp. 45-52, 1996.

[358] M. Hikita, M. Matsuoka, R. Shimizu, K. Kato, N. Hayakawa, H. Okubo, "Kerr electro-optic field mapping and charge dynamics in impurity-doped transformer oil," IEEE Transactions on Dielectrics and Electrical Insulation, vol. 3, no. 1, pp. 80-86, 1996.

[359] A.P. Washabaugh, M. Zahn, "Flow electrification measurements of transformer insulation using a Couette flow facility," IEEE Transactions on Dielectrics and Electrical Insulation, vol. 3, no. 2, pp. 161-181, 1996.

[360] I.A. Metwally, "Characterization of static electrification in power transformers," IEEE Transactions on Dielectrics and Electrical Insulation, vol. 3, no. 2, pp. 307-315, 1996.

[361] S. Jayaram, "Effect of streaming potential on heat transfer in transformer oil," IEEE Transactions on Dielectrics and Electrical Insulation, vol. 3, no. 3, pp. 410-416, 1996.

[362] A. Saker, P. Atten, "Properties of streamers in transformer oil," IEEE Transactions on Dielectrics and Electrical Insulation, vol. 3, no. 6, pp. 784-791, 1996.

[363] L.W. Pierce, "Transformer design and application considerations for nonsinusoidal load currents," IEEE Transactions on Industry Applications, vol. 32, no. 3, pp. 633-645, 1996.

[364] W.H. Kersting, W.H. Phillips, "Modeling and analysis of unsymmetrical transformer banks serving unbalanced loads," IEEE Transactions on Industry Applications, vol. 32, no. 3, pp. 720-725, 1996.

[365] J.-P. Keradec, B. Cogitore, F. Blache, "Power transfer in a two-winding transformer: from 1-D propagation to an equivalent circuit," IEEE Trans. Magn., vol. 32, no. 1, pp. 274-280, 1996.

[366] M. Elleuch, M. Poloujadoff, "A contribution to the modeling of three phase transformers using reluctances," IEEE Trans. Magn., vol. 32, no. 1, pp. 335-343, 1996.

[367] C. Guerin, G. Meunier, G. Tanneau, "Surface impedance for 3D nonlinear eddy current problems-application to loss computation in transformers," IEEE Trans. Magn., vol. 32, no. 3, pp. 808-811, 1996.

[368] N. Esposito, A. Musolino, M. Raugi, "Equivalent network model for magnetic field and circuital analysis of transformers including hysteresis effects," IEEE Trans. Magn., vol. 32, no. 3, pp. 1094-1097, 1996.

[369] M. Pietruszka, E. Napieralska-Juszczak, "Lamination of T-joints in the transformer core," IEEE Trans. Magn., vol. 32, no. 3, pp. 1180-1183, 1996.

[370] K. Zakrzewski, B. Tomczuk, "Magnetic field analysis and leakage inductance calculation in current transformers by means of 3-D integral methods," IEEE Trans. Magn., vol. 32, 
no. 3, pp. 1637-1640, 1996.

[371] T. Renyuan, L. Yan, L. Feng, T. Lijian, "Resultant magnetic fields due to both windings and heavy current leads in large power transformers," IEEE Trans. Magn., vol. 32, no. 3, pp. 1641-1644, 1996.

[372] T. Nitta, K. Misawa, H. Nomura, "Some considerations on superconducting transformers from a design-point of view," IEEE Trans. Magn., vol. 32, no. 4, pp. 2381-2384, 1996.

[373] T. Kanada, M. Enokizono, K. Kawamura, J.D. Sievert, "Distributions on localized iron loss of three-phase amorphous transformer model core by using two-dimensional magnetic sensor," IEEE Trans. Magn., vol. 32, no. 5, pp. 4797-4799, 1996.

[374] M. Imamura, M. Tokubuchi, "Magnetic field analysis for the optical current-transformer used for three-phase bus-bars arranged longitudinally," IEEE Trans. Magn., vol. 32, no. 5, pp. 4962-4964, 1996

[375] H. Tsujimoto, T. Koiso, "Characteristic in the $0.01 \mathrm{GHz}-2.6$ $\mathrm{GHz}$ range of film transformer with coils on both sides of flexible polyamide film," IEEE Trans. Magn., vol. 32, no. 5, pp. 4980-4982, 1996.

[376] H. Sakamoto, S. Washimiya, "Magnetic coupled power and data transferring system with a detachable transformer," IEEE Trans. Magn., vol. 32, no. 5, pp. 4983-4985, 1996.

[377] Y. Sakamoto, M. Ohta, M. Natsusaka, K. Murakami, "Performance of a miniaturized planar parametric transformer having an excellent voltage regulation," IEEE Trans. Magn., vol. 32, no. 5, pp. 4995-4997, 1996.

[378] A.W. Galli, M.D. Cox, “Temperature rise of small oil-filled distribution transformers supplying nonsinusoidal load currents," IEEE Trans. Power Delivery, vol. 11, no. 1, pp. 283-291, 1996

[379] E.F. Fuchs, R. Fei, “A new computer-aided method for the efficiency measurement of low-loss transformers and inductors under nonsinusoidal operation," IEEE Trans. Power Delivery, vol. 11, no. 1, pp. 292-304, 1996.

[380] M.T. Bishop, J.F. Baranowski, D. Heath, S.J. Benna, "Evaluating harmonic-induced transformer heating," IEEE Trans. Power Delivery, vol. 11, no. 1, pp. 305-311, 1996.

[381] W.P. Seitlinger, H. Foschum, L.B. Wagenaar, J.A. Fleeman, "Investigations of an EHV autotransformer tested with open and arrester terminated terminals," IEEE Trans. Power Delivery, vol. 11, no. 1, pp. 312-322, 1996.

[382] Bin-Kwie Chen, Bing-Song Guo, "Three phase models of specially connected transformers," IEEE Trans. Power Delivery, vol. 11, no. 1, pp. 323-330, 1996.

[383] N.E. Frost, P.B. McGrath, C.W. Burns, "Investigation into the effect of transformer oil on polymers," IEEE Trans. Power Delivery, vol. 11, no. 1, pp. 331-334, 1996.

[384] Tsai-Hsiang Chen, Yung-Liang Chang, "Integrated models of distribution transformers and their loads for three-phase power flow analyses," IEEE Trans. Power Delivery, vol. 11, no. 1 , pp. 507-513, 1996.

[385] A.S. Morched, L. Marti, R.H. Brierley, J.G. Lackey, “Analysis of internal winding stresses in EHV generator step-up transformer failures," IEEE Trans. Power Delivery, vol. 11, no 2, pp. 888-894, 1996.

[386] E. Takahashi, K. Tanaka, K. Toda, M. Ikeda, T. Teranishi, M. Inaba, T. Yanari, "Development of large-capacity gas-insulated transformer," IEEE Trans. Power Delivery, vol. 11, no. 2, pp. 895-902, 1996.

[387] M. Nakadate, K. Toda, K. Sato, D. Biswas, C. Nakagawa, T. Yanari, "Gas cooling performance in disc winding of large-capacity gas-insulated transformer," IEEE Trans. Power Delivery, vol. 11, no. 2, pp. 903-908, 1996.

[388] K. Mizuno, A. Ogawa, E. Ooe, E. Mori, "Diagnostic techniques and apparatus for detecting faults in perfluorocarbon liquid immersed transformers," IEEE Trans. Power Delivery, vol. 11, no. 2, pp. 909-916, 1996.

[389] H. Yamaguchi, Y. Sato, T. Kataoka, "Conceptual design of air-core superconducting power transformer for cable transmission system," IEEE Trans. Power Delivery, vol. 11, no. 2, pp. 917-923, 1996.

[390] C. Bengtsson, "Status and trends in transformer monitoring," IEEE Trans. Power Delivery, vol. 11, no. 3, pp. 1379-1384, 1996.

[391] R. Batruni, R.C. Degeneff, M.A. Lebow, "Determining the effect of thermal loading on the remaining useful life of a power transformer from its impedance versus frequency characteristic," IEEE Trans. Power Delivery, vol. 11, no. 3, pp. 1385-1390, 1996.

[392] T. Nakajima, K.I. Suzuki, M. Yajima, N. Kawakami, K. Tanomura, S. Irokawa, "A new control method preventing transformer DC magnetization for voltage source self-commutated converters," IEEE Trans. Power Delivery, vol. 11 , no. 3 , pp. 1522-1528, 1996.

[393] N. Janssens, T. Van Craenenbroeck, D. Van Dommelen, "Direct calculation of the stability domains of three-phase ferroresonance in isolated neutral networks with grounded neutral voltage transformers," IEEE Trans. Power Delivery, vol. 11, no. 3, pp. 1546-1553, 1996.

[394] X. Chen, "A three-phase multi-legged transformer model in ATP using the directly-formed inverse inductance matrix," IEEE Trans. Power Delivery, vol. 11, no. 3, pp. 1554-1562, 1996.

[395] R. Gutman, L.B. Wagenaar, "EHV transformer bank unbalance: practical issues and solutions," IEEE Trans. Power Delivery, vol. 11, no. 4, pp. 1830-1835, 1996.

[396] Y. Zhang, X. Ding, Y. Liu, P.J. Griffin, “An artificial neural network approach to transformer fault diagnosis," IEEE Trans. Power Delivery, vol. 11, no. 4, pp. 1836-1841, 1996.

[397] W. Enright, J. Arrillaga, A.R. Wood, F. Perez Hidalgo, "The smoothing transformer, a new concept in DC side harmonic reduction of HVDC schemes," IEEE Trans. Power Delivery, vol. 11, no. 4, pp. 1941-1947, 1996.

[398] S. Chen, A.R. Wood, J. Arrillaga, "HVDC converter transformer core saturation instability: a frequency domain analysis," IET Gener. Transm. Distrib., vol. 143, no. 1, pp. 75-81, 1996.

[399] T.-H. Chen, J.-D. Chang, Y.-L. Chang, "Models of grounded mid-tap open-wye and open-delta connected transformers for rigorous analysis of a distribution system," IET Gener. Transm. Distrib., vol. 143, no. 1, pp. 82-88, 1996. 
[400] J.A. Palmer, J.K. Nelson, "Intelligent control of large power transformer cooling pumps," IET Gener. Transm. Distrib., vol. 143 , no. 5 , pp. 474-478, 1996

[401] Q. Xu, A. Refsum, R. Watson, "Application of external compensation to current transformers," IET Science Measurement \& Technology, vol. 143, no. 2, pp. 147-150, 1996.

[402] Z. Radaković, Dj. Kalić, "Results of a novel algorithm for the calculation of the characteristic temperatures in power oil transformers," Electrical Engineering, vol. 80, no. 3, pp. 205-214, 1997.

[403] R. P. Maheshwari, H. K. Verma, "Adaptive digital differential relay of parabolic characteristic for transformer protection," Electric Power Components and Systems, vol. 25, no. 5, pp. 459-473, 1997.

[404] A. Keyhani, H. Tsai, S. Pillutla, A. Abur, "Identification of high frequency transformer model parameters," Electric Power Systems Research, vol. 42, no. 2, pp. 127-133, 1997.

[405] A. Sarić, M. Ćalović, M. Djukanović, "Neural-net based coordinated control of capacitors and ULTC transformer in daily operation of radial distribution systems," Electric Power Systems Research, vol. 43, no. 3, pp. 169-177, 1997.

[406] M. Iwakuma, K. Funaki, H. Shinohara, "Electromagnetic properties in parallel conductors composed of Bi2223 multifilamentary wires for power transformer windings," IEEE Transactions on Applied Superconductivity, vol. 7, no. 2, pp. 298-301, 1997.

[407] K. Funaki, M. Iwakuma, M. Takeo, "Preliminary tests of a $500 \mathrm{kVA}$-class oxide superconducting transformer cooled by subcooled nitrogen," IEEE Transactions on Applied Superconductivity, vol. 7, no. 2, pp. 824-827, 1997.

[408] H. Yamaguchi, T. Kataoka, "Stability analysis of air-core superconducting power transformer," IEEE Transactions on Applied Superconductivity, vol. 7, no. 2, pp. 1013-1016, 1997.

[409] D.E. Kirichenko, A.B. Pavolotskij, O.V. Snigirev, "Integrated two stage dc SQUID-based amplifier with double transformer coupling scheme," IEEE Transactions on Applied Superconductivity, vol. 7, no. 2, pp. 1045-1048, 1997.

[410] D. Ponnusamy, N. Tralshawala, J.R. Claycomb, J.H. Jr. Miller, K. Ravi-Chandar, K. Salama, "Processing and characterization of high $T_{c}$ magnetic shields and flux transformers," IEEE Transactions on Applied Superconductivity, vol. 7, no. 2, pp. 1418-1421, 1997.

[411] S. Kohjiro, T. Kikuchi, S. Kiryu, A. Shoji, "Numerical characterization of impedance transformers consisting of vertically stacked superconducting transmission lines," IEEE Transactions on Applied Superconductivity, vol. 7, no. 2, pp. 2343-2346, 1997.

[412] C. Francke, L. Mex, A. Kramer, "Large area flux transformers and passivation for flip-chip magnetometers," IEEE Transactions on Applied Superconductivity, vol. 7, no. 2, pp. 2768-2771, 1997.

[413] M. N. Keene, N. J. Exon, J. S. Satchell, R. G. Humphreys, N. G. Chew, K. Lander, "HTS SQUID magnetometers with intermediate flux transformers," IEEE Transactions on Applied Superconductivity, vol. 7, no. 2, pp. 3048-3051, 1997.

[414] G.J. Ockenfuss, J. Borgmann, M. Reese, R. Wordenweber,
"Optimization of large-area single-layer flux-transformers and concentrators coupled to RF-SQUIDs in flip-chip geometry," IEEE Transactions on Applied Superconductivity, vol. 7, no. 2, pp. 3698-370, 1997.

[415] H. Okubo, R. Shimizu, A. Sawada, K. Kato, N. Hayakawa, M. Hikita, "Kerr electro-optic field measurement and charge dynamics in transformer-oil/solid composite insulation systems," IEEE Transactions on Dielectrics and Electrical Insulation, vol. 4, no. 1, pp. 64-70, 1997.

[416] I.A. Metwally, "Influence of solid insulating phase on streaming electrification of transformer oil," IEEE Transactions on Dielectrics and Electrical Insulation, vol. 4, no. 3, pp. 327-340, 1997.

[417] Y. Nakao, M. Naruse, Y. Suzuki, H. Itho, Y. Sakai, H. Tagashira, "Influence of insulating barrier on the creepage discharge in transformer oil," IEEE Transactions on Dielectrics and Electrical Insulation, vol. 4, no. 6, pp. 775-779, 1997.

[418] C. Blanco, P.J. Villegas, E. Lopez, “An improved electronic transformer for low-power halogen cycle lamps," IEEE Transactions on Industry Applications, vol. 33, no. 1, pp. 246-251, 1997.

[419] S. Klopper, J.A. Ferreira, "A sensor for balancing flux in converters with a high-frequency transformer link," IEEE Transactions on Industry Applications, vol. 33, no. 3, pp. 774-779, 1997.

[420] L. Kadar, P. Hacksel, J. Wikston, "The effect of current and voltage transformers accuracy on harmonic measurements in electric arc furnaces," IEEE Transactions on Industry Applications, vol. 33, no. 3, pp. 780-783, 1997.

[421] J. Faiz, B. Abed-Ashtiani, M.R. Byat, "Lumped complete equivalent circuit of a coreless high-frequency transformer," IEEE Trans. Magn., vol. 33, no. 1, pp. 703-707, 1997.

[422] T. Egawa, M. Kyono, K. Misawa, "Study of a shunt reactor with transformer function," IEEE Trans. Magn., vol. 33, no. 2, pp. 1235-1238, 1997.

[423] P. Holmberg, A. Bergqvist, G. Engdahl, "Modelling eddy currents and hysteresis in a transformer laminate," IEEE Trans. Magn., vol. 33, no. 2, pp. 1306-1309, 1997.

[424] Y. Higuchi, M. Koizumi, S. Saito, "Three dimensional eddy current calculation with integral equation method for transformers," IEEE Trans. Magn., vol. 33, no. 2, pp. 1310-1313, 1997.

[425] P.-S. Shin, J. Lee, "Magnetic field analysis of amorphous core transformer using homogenization technique," IEEE Trans. Magn., vol. 33, no. 2, pp. 1808-1811, 1997.

[426] T. Tran-Quoc, L. Pierrat, "Correction of the measured core losses under distorted flux [power transformers]," IEEE Trans. Magn., vol. 33, no. 2, pp. 2045-2048, 1997.

[427] C. Xiang, Y. Jinsha, Z. Guoqiang, Z. Yuanlu, H. Qifan, "Analysis of leakage magnetic problems in shell-form power transformer," IEEE Trans. Magn., vol. 33, no. 2, pp. 2049-2052, 1997.

[428] H. Inoue, H. Fusayasu, N. Takahashi, "Investigation of factors affecting crosstalk in a rotary transformer," IEEE Trans. Magn., vol. 33, no. 2, pp. 2215-2218, 1997.

[429] R.J. Jackman, J.A. Rogers, G.M. Whitesides, "Fabrication 
and characterization of a concentric cylindrical microtransformer," IEEE Trans. Magn., vol. 33, no. 2, pp. 2501-2503, 1997.

[430] J.Y. Park, L.K. Lagorce, M.G. Allen, "Ferrite-based integrated planar inductors and transformers fabricated at low temperature," IEEE Trans. Magn., vol. 33, no. 5, pp. 3322-3324, 1997.

[431] T. Yanada, O. Ichinokura, "High performance step-down noise-reduction transformer constructed with C-core," IEEE Trans. Magn., vol. 33, no. 5, pp. 3331-3333, 1997.

[432] K. Tajima, A. Kaga, O. Ichinokura, "Transient analysis of a push-pull parametric transformer at start-up time," IEEE Trans. Magn., vol. 33, no. 5, pp. 3334-3336, 1997.

[433] N. Subramanian, "Analysis and design of a new breed of constant voltage transformers," IEEE Trans. Magn., vol. 33, no. 5, pp. 3337-3339, 1997.

[434] M. Imamura, M. Nakahara, S. Tamura, "Output characteristics of field sensor used for optical current transformers applied to the flat-shape three-phase bus-bar," IEEE Trans. Magn., vol. 33, no. 5, pp. 3403-3405, 1997.

[435] Y. Yamamoto, A. Makino, T. Yamaguchi, I. Sasada, "Fine grained ferrite for low profile transformer," IEEE Trans. Magn., vol. 33, no. 5, pp. 3742-3744, 1997.

[436] M. Enokizono, N. Soda, "Finite element analysis of transformer model core with measured reluctivity tensor," IEEE Trans. Magn., vol. 33, no. 5, pp. 4110-4111, 1997.

[437] M. Elleuch, M. Poloujadoff, “Anisotropy in three-phase transformer circuit model," IEEE Trans. Magn., vol. 33, no. 5, pp. 4319-4326, 1997.

[438] T. Fujimoto, M. Shimizu, H. Nakagawa, I. Sone, K. Kawashima, E. Mori, "Development of an optical current transformer for adjustable speed pumped storage systems," IEEE Trans. Power Delivery, vol. 12, no. 1, pp. 45-50, 1997.

[439] Y.C. Kang, J.K. Park, S.H. Kang, A.T. Johns, R.K. Aggarwal, "An algorithm for compensating secondary currents of current transformers," IEEE Trans. Power Delivery, vol. 12, no. 1, pp. 116-124, 1997.

[440] J.R. Marti, L.R. Linares, H.W. Dommel, "Current transformers and coupling-capacitor voltage transformers in real-time simulations," IEEE Trans. Power Delivery, vol. 12, no. 1, pp. 164-168, 1997.

[441] O.M. Zodeh, R.J. Whearty, "Thermal characteristics of a meta-aramid and cellulose insulated transformer at loads beyond nameplate," IEEE Trans. Power Delivery, vol. 12, no. 1, pp. 234-248, 1997.

[442] B.C. Lesieutre, W.H. Hagman, J.L. Jr. Kirtley, “An improved transformer top oil temperature model for use in an on-line monitoring and diagnostic system," IEEE Trans. Power Delivery, vol. 12, no. 1, pp. 249-256, 1997.

[443] P. Picher, L. Bolduc, A. Dutil, V.O Pham, "Study of the acceptable DC current limit in core-form power transformers," IEEE Trans. Power Delivery, vol. 12, no. 1, pp. 257-265, 1997.

[444] J. Jalbert, R. Gilbert, "Decomposition of transformer oils: a new approach for the determination of dissolved gases," IEEE Trans. Power Delivery, vol. 12, no. 1, pp. 754-760, 1997.
[445] Yann-Chang Huang, Hong-Tzer Yang, Ching-Lien Huang, "Developing a new transformer fault diagnosis system through evolutionary fuzzy logic," IEEE Trans. Power Delivery, vol. 12, no. 2, pp. 761-767, 1997.

[446] T. Stensland, E.F. Fuchs, W.M. Grady, M.T. Doyle, "Modeling of magnetizing and core-loss currents in single-phase transformers with voltage harmonics for use in power flow," IEEE Trans. Power Delivery, vol. 12, no. 2, pp. 768-774, 1997.

[447] X. Chen, S.S. Venkata, "A three-phase three-winding core-type transformer model for low-frequency transient studies," IEEE Trans. Power Delivery, vol. 12, no. 2, pp. 775-782, 1997.

[448] C. Hochgraf, R.H. Lasseter, "A transformer-less static synchronous compensator employing a multi-level inverter," IEEE Trans. Power Delivery, vol. 12, no. 2, pp. 881-887, 1997.

[449] K. Yabe, "Power differential method for discrimination between fault and magnetizing inrush current in transformers," IEEE Trans. Power Delivery, vol. 12, no. 2, pp. 1110-1118, 1997.

[450] B. Kasztenny, E. Rosolowski, M.M. Saha, B. Hillstrom, “A self-organizing fuzzy logic based protective relay-an application to power transformer protection," IEEE Trans. Power Delivery, vol. 12, no. 3, pp. 1119-1127, 1997.

[451] J. Pihler, B. Grcar, D. Dolinar, "Improved operation of power transformer protection using artificial neural network," IEEE Trans. Power Delivery, vol. 12, no. 3, pp. 1128-1136, 1997.

[452] J.M. Lunsford, T.J. Tobin, "Detection of and protection for internal low-current winding faults in overhead distribution transformers," IEEE Trans. Power Delivery, vol. 12, no. 3, pp. 1241-1249, 1997.

[453] M. Takahashi, H. Noda, K. Terai, "Optical current transformer for gas insulated switchgear using silica optical fiber," IEEE Trans. Power Delivery, vol. 12, no. 3, pp. 1422-1427, 1997.

[454] Kwang-Chang Lu, Nanming Chen, "The phasor combination differential protection for Le-Blanc transformers," IEEE Trans. Power Delivery, vol. 12, no. 3, pp. 1434-1438, 1997.

[455] T. Hasegawa, M. Hatano, K. Yamaji, "Dielectric strength of transformer insulation at DC polarity reversal," IEEE Trans. Power Delivery, vol. 12, no. 4, pp. 1526-1531, 1997.

[456] O.W. Andersen, "Large transformers for power electronic loads," IEEE Trans. Power Delivery, vol. 12, no. 4, pp. 1532-1537, 1997.

[457] M.F. Lachman, Y.N. Shafir, "Influence of single-phase excitation and magnetizing reactance on transformer leakage reactance measurement," IEEE Trans. Power Delivery, vol. 12, no. 4, pp. 1538-1546, 1997.

[458] T.K. Saha, M. Darveniza, D.J.T. Hill, T.T. Le, "Electrical and chemical diagnostics of transformers insulation. A. Aged transformer samples," IEEE Trans. Power Delivery, vol. 12, no. 4, pp. 1547-1554, 1997.

[459] T.K. Saha, M. Darveniza, D.J.T. Hill, T.T. Le, "Electrical and chemical diagnostics of transformers insulation. B. Accelerated aged insulation samples," IEEE Trans. Power Delivery, vol. 12, no. 4, pp. 1555-1561, 1997. 
[460] P.T. Staats, W.M. Grady, A. Arapostathis, R.S. Thallam, “A procedure for derating a substation transformer in the presence of widespread electric vehicle battery charging," IEEE Trans. Power Delivery, vol. 12, no. 4, pp. 1562-1568, 1997.

[461] T. Hasman, "Reflection and transmission of traveling waves on power transformers," IEEE Trans. Power Delivery, vol. 12, no. 4, pp. 1684-1689, 1997.

[462] J.A. Jardini, C.M.V. Tahan, S.U. Ahn, E.L. Ferrari, "Distribution transformer loading evaluation based on load profiles measurements," IEEE Trans. Power Delivery, vol. 12, no. 4, pp. 1766-1770, 1997.

[463] J. Arrillaga, W. Enright, N.R. Watson, A.R. Wood, "Improved simulation of HVDC converter transformers in electromagnetic transient programs," IET Gener. Transm. Distrib., vol. 144, no. 2, pp. 100-106, 1997.

[464] Z. Emin, B.A.T. Al Zahawi, D.W. Auckland, Y.K. Tong, "Ferroresonance in electromagnetic voltage transformers: A study based on nonlinear dynamics" IET Gener. Transm. Distrib., vol. 144, no. 4, pp. 383-387, 1997.

[465] S. Mozaffari, M. Sameti, A.C. Soudack, "Effect of initial conditions on chaotic ferroresonance in power transformers," IET Gener. Transm. Distrib., vol. 144, no. 5, pp. 456-460, 1997.

[466] Y. Shibuya, S. Fujita, N. Hosokawa, "Analysis of very fast transient overvoltage in transformer winding," IET Gener. Transm. Distrib., vol. 144, no. 5, pp. 461-468, 1997.

[467] M.R. Salem, L.A. Talat, H.M. Soliman, "Voltage control by tap-changing transformers for a radial distribution network," IET Gener. Transm. Distrib., vol. 144, no. 6, pp. 517-520, 1997.

[468] D.A. Koppikar, S.V. Kulkarni, S.A. Khaparde, S.K. Jha, "Evaluation of eddy losses due to high current leads in transformers," IET Science Measurement \& Technology, vol. 144, no. 1, pp. 34-38, 1997.

[469] W. Xu, D. Wang, Z. Zhou, H. Chen, "Fault diagnosis of power transformers: application of fuzzy set theory, expert systems and artificial neural networks," IET Science Measurement \& Technology, vol. 144, no. 1, pp. 39-44, 1997.

[470] G.Y. Tian, Z.X. Zhao, R.W. Baines, N. Zhang, "Computational algorithms for linear variable differential transformers (LVDTs)," IET Science Measurement \& Technology, vol. 144, no. 4, pp. 189-192, 1997.

[471] Ji Jwo-Hwu, "The refined strategy for substation main transformer and feeder load balancing," International Journal of Electrical Power \& Energy Systems, vol. 19, no. 2, pp. 87-91, 1997.

[472] J. Faiz, M. Ojaghi, "A fast boundary element method to electric field computation within the tank of power transformers," COMPEL, vol. 17, no. 1, pp. 69-77, 1998.

[473] P. Di Barba, U. Piovan, A. Savini, "Optimal shape design of the HV winding of a test transformer," COMPEL, vol. 17, no. 1, pp. 128-134, 1998.

[474] K. Komeza, H. Welfle, S. Wiak, "Transient states analysis of 3D transformer structure," COMPEL, vol. 17, no. 2, pp. 252-256, 1998.

[475] E. Lesniewska, "A field analysis of an overcurrent state and an incidental break in the secondary circuit of a current transformer," COMPEL, vol. 17, no. 2, pp. 267-272, 1998.

[476] M. Lukaniszyn, R. Unbehauen, "The analysis of the leakage reactance in a one-phase transformer with asymmetrical disk-type windings," COMPEL, vol. 17, no. 2, pp. 285-289, 1998.

[477] A. Pelikant, J. Turowski, "Field and power loss distribution on covers of power transformers," COMPEL, vol. 17, no. 3, pp. 302-306, 1998.

[478] G. Cannistrà, A. Covitti, M. Sylos Labini, "An easy and fast 2D finite element program for studying the fields in three-phase transformers," COMPEL, vol. 17, no. 3, pp. 342-346, 1998.

[479] Z. Cheng, S. Gao, J. Wang, H. He, Z. Liu, M. Wu, H. Li, Q. $\mathrm{Hu}$, "Loss evaluation of non-magnetic tie-plates in transformers," COMPEL, vol. 17, no. 3, pp. 347-351, 1998.

[480] K. Najdenkoski, D. Manov, "Electromagnetic forces calculation on power transformer windings under short circuit," COMPEL, vol. 17, no. 3, pp. 374-377, 1998.

[481] K. Zakrzewski, M. Lukaniszyn, B. Tomczuk, "3-D calculations of leakage field and reactance for special transformers," COMPEL, vol. 17, no. 4, pp. 460-474, 1998.

[482] G. Lupò, C. Petrarca, L. Egiziano, V. Tucci, M. Vitelli, "Partial discharge testing on resin insulated voltage transformers," Electrical Engineering, vol. 81, no. 2, pp. 89-97, 1998.

[483] S. Skundric, V. Radenkovic, "Instrument transformer accuracy testing by the two-phase conversion method," Electrical Engineering, vol. 81, no. 4, pp. 241-244, 1998.

[484] M. Z. EL-Sadek, M. M. Dessouky, G. A. Mahmoud, W. I. Rashed, "Combined use of tap-changing transformer and static VAR compensator for enhancement of steady-state voltage stabilities," Electric Power Systems Research, vol. 45, no. 1 , pp. 47-55, 1998.

[485] T. Leibfried, "Online monitors keep transformers in service," IEEE Computer Applications in Power Magazine, vol. 11, no. 3, pp. 36-42, 1998.

[486] B. Kasztenny, M. Kezunovic, "Digital relays improve protection of large transformers," IEEE Computer Applications in Power Magazine, vol. 11, no. 4, pp. 39-45, 1998.

[487] P. Love, "Correlation of Fourier transforms of pulsed electric field waveform and microorganism inactivation," IEEE Transactions on Dielectrics and Electrical Insulation, vol. 5, no. 1, pp. 142-147, 1998.

[488] R. Blue, D. Uttamchandani, O. Farish, "Infrared detection of transformer insulation degradation due to accelerated thermal aging," IEEE Transactions on Dielectrics and Electrical Insulation, vol. 5, no. 2, pp. 165-168, 1998.

[489] I.A. Metwally, "Flow electrification of transformer oil effects of mixed fields," IEEE Transactions on Dielectrics and Electrical Insulation, vol. 5, no. 4, pp. 518-526, 1998.

[490] M.-B. Fatmi, A. Bui, C. Boisdon, P. Vuarchex, "PPS electrical properties for power transformers," IEEE Transactions on Dielectrics and Electrical Insulation, vol. 5, no. 4, pp. 618-621, 1998.

[491] J.M. Lehr, F.J. Agee, R. Copeland, W.D. Prather, "Mea- 
surement of the electric breakdown strength of transformer oil in the sub-nanosecond regime," IEEE Transactions on Dielectrics and Electrical Insulation, vol. 5, no. 6, pp. 857-861, 1998.

[492] R. Blue, D. Uttamchandani, O. Farish, "The determination of FFA concentration in transformer oil by fluorescence measurements," IEEE Transactions on Dielectrics and Electrical Insulation, vol. 5, no. 6, pp. 892-895, 1998.

[493] O. Koreh, K. Torkos, M. Bashir Mahara, Jozsef Borossay, Vladislav lzvekov "Study of water clusters in insulating oils by Fourier transform infrared spectroscopy," IEEE Transactions on Dielectrics and Electrical Insulation, vol. 5, no. 6, pp. 896-902, 1998

[494] A. Losi, V. Mangoni, M. Russo, "Optimal exploitation of generator-transformer units," IEEE Transactions on Energy Conversion, vol. 13, no. 1, pp. 90-95, 1998.

[495] P.K. Dooley, "A comparison of liquid-filled and dry-type transformers for industrial applications," IEEE Transactions on Industry Applications, vol. 34, no. 1, pp. 222-226, 1998.

[496] M.M. Swamy, S.L. Rossiter, "Harmonic interaction between $1500 \mathrm{kVA}$ supply transformer and VFD load at an industrial plant," IEEE Transactions on Industry Applications, vol. 34, no. 5, pp. 897-903, 1998.

[497] B. Postma, T. Vinay, T. Kangsanant, A. Harvey, "Electromagnetic flat-faced robot gripper for handling multiple industrial transformer core lamination plates," IEEE Trans. Magn., vol. 34, no. 3, pp. 700-707, 1998.

[498] A.J. Moses, "Comparison of transformer loss prediction from computed and measured flux density distribution," IEEE Trans. Magn., vol. 34, no. 4, pp. 1186-1188, 1998.

[499] S. Sieradzki, R. Rygal, M. Soinski, "Apparent core losses and core losses in five-limb amorphous transformer of $160 \mathrm{kVA}$," IEEE Trans. Magn., vol. 34, no. 4, pp. 1189-1191, 1998.

[500] V. Molcrette, J.-L. Kotny, J.-P. Swan, J.-F. Brudny, "Reduction of inrush current in single-phase transformer using virtual air gap technique," IEEE Trans. Magn., vol. 34, no. 4, pp. 1192-1194, 1998

[501] F. Robert, P. Mathys, J.-P. Schauwers, "Ohmic losses calculation in SMPS transformers: numerical study of Dowell's approach accuracy," IEEE Trans. Magn., vol. 34, no. 4, pp. $1255-1257,1998$.

[502] Junwei Lu, F.P. Dawson, S. Yamada, "Application and analysis of adjustable profile high frequency switchmode transformer having a U-shaped winding structure," IEEE Trans. Magn., vol. 34, no. 4, pp. 1345-1347, 1998.

[503] N. Nishizuka, M. Sato, Y. Li, "Analysis of frequency characteristics of small-sized wide-band compound transformers," IEEE Trans. Magn., vol. 34, no. 4, pp. 1348-1350, 1998.

[504] T. Yanada, S. Minowa, O. Ichinokura, S. Kikuchi, "Design and analysis of noise-reduction transformer based on equivalent circuit," IEEE Trans. Magn., vol. 34, no. 4, pp. 1351-1353, 1998.

[505] Y. Sakamoto, M. Ohta, M. Natsusaka, K. Murakami, “An analytical method of a planar parametric transformer based on the magnetic circuit model," IEEE Trans. Magn., vol. 34, no. 4, pp. 1354-1356, 1998.

[506] H. Tsujimoto, "Design and simulation of film transformer on flexible polyamide film in very high frequency range," IEEE Trans. Magn., vol. 34, no. 4, pp. 1357-1359, 1998.

[507] J.Y Park, M.G. Allen, "Packaging-compatible microinductors and microtransformers with screen-printed ferrite using low temperature processes," IEEE Trans. Magn., vol. 34, no. 4, pp. 1366-1368, 1998.

[508] Ming Xu, T.M. Liakopoulos, C.H. Ahn, Suk Hee Han, Hi Jung Kim, "A microfabricated transformer for high-frequency power or signal conversion," IEEE Trans. Magn., vol. 34, no. 4, pp. 1369-1371, 1998.

[509] L.H. Rissing, S.A. Zielke, H.H. Gatzen, "Inductive microtransformer exploiting the magnetoelastic effect," IEEE Trans. Magn., vol. 34, no. 4, pp. 1378-1380, 1998.

[510] T. Fujiwara "Planar integrated magnetic component with transformer and inductor using multilayer printed wiring board," IEEE Trans. Magn., vol. 34, no. 4, pp. 2051-2053, 1998.

[511] E. Steingroever, G. Ross, "A 42-Tesla pulse transformer with a mechanically high resistant field former," IEEE Trans. Magn., vol. 34, no. 4, pp. 2084-2086, 1998.

[512] M. Imamura, M. Nakahara, T. Yamaguchi, S. Tamura, "Analysis of magnetic fields due to three-phase bus bar currents for the design of an optical current transformer," IEEE Trans. Magn., vol. 34, no. 4, pp. 2274-2279, 1998.

[513] A.C. Delaiba, J.C. de Oliveira, J.R. Cardoso, S.Y. Nabeta, "Behavior of three-phase transformers supplying non linear loads using time domain representation and finite element analysis," IEEE Trans. Magn., vol. 34, no. 4, pp. 3174-3177, 1998.

[514] Y. Kawase, T. Mori, T. Ota, "Magnetic field analysis of coupling transformers for electric vehicle using 3-D finite element method," IEEE Trans. Magn., vol. 34, no. 4, pp. 3186-3189, 1998.

[515] Jiayu Lu, Jiansheng Yuan, Li Chen, Jianni Sheng, Xinshan $\mathrm{Ma}$, "Calculation of the short-circuit reactance of transformers by a line integral based on surface magnetic charges," IEEE Trans. Magn., vol. 34, no. 5, pp. 3483-3486, 1998.

[516] Li Lin, Cui Xiang, Zhang Yuanlu, Cheng Zhiguang, Zhang Guoqiang, Zhao Yinhan, "Losses calculation in transformer tie plate using the finite element method," IEEE Trans. Magn., vol. 34 , no. 5, pp. 3644-3647, 1998.

[517] M. Elleuch, M. Poloujadoff, "New transformer model including joint air gaps and lamination anisotropy," IEEE Trans. Magn., vol. 34, no. 5, pp. 3701-3711, 1998.

[518] J. Izykowski, B. Kasztenny, E. Rosolowski, M.M. Saha, B. Hillstrom, "Dynamic compensation of capacitive voltage transformers," IEEE Trans. Power Delivery, vol. 13, no. 1, pp. $116-122,1998$

[519] G.B. Gharehpetian, H. Mohseni, K. Moller, "Hybrid modelling of inhomogeneous transformer winding for very fast transient overvoltage studies," IEEE Trans. Power Delivery, vol. 13, no. 1, pp. 157-163, 1998.

[520] B. Kasztenny, E. Rosolowski, J. Izykowski, M. M. Saha, B. Hillstrom, "Fuzzy logic controller for on-load transformer tap changer," IEEE Trans. Power Delivery, vol. 13, no. 1, pp. 164-170, 1998

[521] M.A. Rahman, B. So, M.R. Zaman, M.A. Hoque, "Testing of 
algorithms for a stand-alone digital relay for power transformers," IEEE Trans. Power Delivery, vol. 13, no. 2, pp. 374-385, 1998.

[522] S. Uchida, K. Mochizuki, K. Araki, I. Kaku, Y. Sakuraba, T. Takeshina, S. Shirakawa, "Relation of insulation resistance and deteriorated ratio of reference voltage of oil-immersed surge arrester elements enclosed in pole transformers," IEEE Trans. Power Delivery, vol. 13, no. 2, pp. 453-458, 1998.

[523] M.R. Zaman, M.A. Rahman, "Experimental testing of the artificial neural network based protection of power transformers," IEEE Trans. Power Delivery, vol. 13, no. 2, pp. 510-517, 1998.

[524] A. Kramer, J. Ruff, "Transformers for phase angle regulation considering the selection of on-load tap-changers," IEEE Trans. Power Delivery, vol. 13, no. 2, pp. 518-525, 1998.

[525] R.S. Girgis, E.G. te Nijenhuis, K. Gramm, J.-E. Wrethag, "Experimental investigations on effect of core production attributes on transformer core loss performance," IEEE Trans. Power Delivery, vol. 13, no. 2, pp. 526-531, 1998.

[526] G.F. Mechler, R.S. Girgis, "Calculation of spatial loss distribution in stacked power and distribution transformer cores," IEEE Trans. Power Delivery, vol. 13, no. 2, pp. 532-537, 1998.

[527] M.R. Iravani, X. Wang, I. Polishchuk, "Digital time-domain investigation of transient behaviour of coupling capacitor voltage transformer," IEEE Trans. Power Delivery, vol. 13, no. 2, pp. 622-629, 1998.

[528] B. Gustavsen, A. Semlyen, "Application of vector fitting to state equation representation of transformers for simulation of electromagnetic transients," IEEE Trans. Power Delivery, vol. 13, no. 3, pp. 834-842, 1998.

[529] R. Dahlgren, G. Rosenwald, C.C. Liu, S. Muchlinski, A. Eide, D. Sobajic, "Model-based synthesis and suppression of transformer alarms in a control center environment," IEEE Trans. Power Delivery, vol. 13, no. 3, pp. 843-848, 1998.

[530] C.J. Hatziadoniu, F.E. Chalkiadakis, "A transformerless high-pulse static synchronous compensator based on the 3-level GTO-inverter," IEEE Trans. Power Delivery, vol. 13, no. 3, pp. 883-888, 1998.

[531] O. Demirci, D.A. Torrey, R.C. Degeneff, "A new approach to solid-state on load tap changing transformers," IEEE Trans. Power Delivery, vol. 13, no. 3, pp. 952-961, 1998.

[532] B. Kasztenny, E. Rosolowski, "Two new measuring algorithms for generator and transformer relaying," IEEE Trans. Power Delivery, vol. 13, No 4, pp. 1053-1059, 1998.

[533] S.K. Pandey, L. Satish, "Multiresolution signal decomposition: a new tool for fault detection in power transformers during impulse tests," IEEE Trans. Power Delivery, vol. 13, no. 4, pp. 1194-1200, 1998.

[534] S. Fujita, N. Hosokawa, Y. Shibuya, "Experimental investigation of high frequency voltage oscillation in transformer windings," IEEE Trans. Power Delivery, vol. 13, no. 4, pp. 1201-1207, 1998.

[535] S. Bellorini, M. Salvetti, F. Bettinali, G. Zafferani, "Seismic qualification of transformer high voltage bushings," IEEE Trans. Power Delivery, vol. 13, no. 4, pp. 1208-1213, 1998.

[536] M. Darveniza, T.K. Saha, D.J.T. Hill, T.T. Le, “Investigations into effective methods for assessing the condition of insulation in aged power transformers," IEEE Trans. Power Delivery, vol. 13, no. 4, pp. 1214-1223, 1998.

[537] Z. Wang, Y. Liu, P.J. Griffin, “A combined ANN and expert system tool for transformer fault diagnosis," IEEE Trans. Power Delivery, vol. 13, no. 4, pp. 1224-1229, 1998.

[538] M.R. Aghaebrahimi, R.W. Menzies, "A customized air-core transformer for a small power tapping station," IEEE Trans. Power Delivery, vol. 13, no. 4, pp. 1265-1270, 1998.

[539] D.J. Tylavsky, N.R. Tatikonda, K. Alteneder, K.E. Brown, "Effects of topology and feeder capacity on substation distribution transformer loading," IEEE Trans. Power Delivery, vol. 13, no. 4, pp. 1425-1431, 1998.

[540] J. Nahman, M. Zlatanoski, "Risk of fatal electric shocks at distribution network MV/LV transformer stations," IET Gener. Transm. Distrib., vol. 145, no. 4, pp. 463-467, 1998.

[541] B.S. Ram, "Loss and current distribution in foil windings of transformers," IET Gener. Transm. Distrib., vol. 145, no. 6, pp. 709-716, 1998.

[542] B.A.T. Al Zahawi, Z. Emin, Y.K. Tong, "Chaos in ferroresonant wound voltage transformers: effect of core losses and universal circuit behaviour," IET Science Measurement \& Technology, vol. 145, no. 1, pp. 39-43, 1998.

[543] R. Blue, P. Conlin, D. Uttamchandani, O. Farish, "Portable optoelectronic instrument for measuring furfuraldehyde in transformer oil," IET Science Measurement \& Technology, vol. 145 , no. 2, pp. 45-48, 1998.

[544] L. Satish, "Short-time Fourier and wavelet transforms for fault detection in power transformers during impulse tests," IET Science Measurement \& Technology, vol. 145, no. 2, pp. 77-84, 1998.

[545] D.A. Koppikar, S.V. Kulkarni, G. Ghosh, S.M. Ainapure, J.S. Bhavsar, "Circulating-current loss in transformer windings," IET Science Measurement \& Technology, vol. 145, no. 4, pp. 136-140, 1998.

[546] Chao-Shun Chen, Tsung-Hsien Wu, "Optimal distribution transformer sizing by dynamic programming," International Journal of Electrical Power \& Energy Systems, vol. 20, no. 3, pp. 161-167, 1998.

[547] D. A. Koppikar, S. V. Kulkarni, S. A. Khaparde, B. Arora, "A modified approach to overfluxing analysis of transformers," International Journal of Electrical Power \& Energy Systems, vol. 20, no. 4, pp. 235-239, 1998.

[548] M. Zielichowski, M. Fulczyk, "Influence of voltage transformers on operating conditions of ground-fault protection system for unit-connected generator," International Journal of Electrical Power \& Energy Systems, vol. 20, no. 5, pp. 313-319, 1998.

[549] N. Hatziargyriou, P. Georgilakis, D. Spiliopoulos, J. Bakopoulos, "Quality improvement of individual cores of distribution transformers using decision trees," International Journal of Engineering Intelligent Systems for Electrical Engineering and Communications, vol. 6, no. 3, pp. 141-146, 1998.

[550] P.S. Georgilakis, N.D. Hatziargyriou, N.D. Doulamis, A.D. Doulamis, S.D. Kollias, "Prediction of iron losses of wound core distribution transformers based on artificial neural net- 
works," Neurocomputing, vol. 23, no. 1-3, pp. 15-29, 1998.

[551] T. Leibfried, "A new method to calculate thermally balanced windings of power transformers," Electrical Engineering, vol. 81, no. 6, pp. 409-412, 1999.

[552] C. S. Chang, J. S. Huang, "Centralized Control of Transformer Tap Changing for Voltage Stability Enhancement," Electric Power Components and Systems, vol. 27, no. 10, pp. 1041-1054, 1999.

[553] Tsai-Hsiang Chen, Mao-Yuan Huang, "Network modeling of 24-pulse rectifier transformers for rigorous simulation of rail transit power systems," Electric Power Systems Research, vol. 50, no. 1 , pp. 23-33, 1999.

[554] A. S. Farag, M. H. Shewhdi, X. Jin, C. Wang, T. C. Cheng, X. Dong, S. Gao, W. Jing, Z. Wang, "On-line partial discharge calibration and monitoring for power transformers," Electric Power Systems Research, vol. 50, no. 1, pp. 47-54, 1999.

[555] G. El-Saady, "A variable structure static phase shifting transformer for power system stabilization," Electric Power Systems Research, vol. 50, no. 1, pp. 71-78, 1999.

[556] M. Z. El-Sadek, G. A. Mahmoud, M. M. Dessouky, W. I. Rashed, "Tap changing transformer role in voltage stability enhancement," Electric Power Systems Research, vol. 50, no. 1, pp. 115-118, 1999.

[557] J.G. Vlachogiannis, “An accurate autotransformer model for load flow studies effect on the steady-state analysis of the Hellenic transmission system," Electric Power Systems Research, vol. 50, no. 2, pp. 147-153, 1999.

[558] M.A.A. Wahab, M.M. Hamada, A.G. Zeitoun, G. Ismail, "Novel modeling for the prediction of aged transformer oil characteristics," Electric Power Systems Research, vol. 51, no. 1, pp. 61-70, 1999.

[559] P. Georgilakis, N. Hatziargyriou, D. Paparigas, "AI helps reduce transformer iron losses," IEEE Computer Applications in Power Magazine, vol. 12, no. 4, pp. 41-46, 1999.

[560] S.W. Schwenterly, B.W. McConnell, J.A. Demko, A. Fadnek, J. Hsu, F.A. List, M.S. Walker, D.W. Hazelton, F.S. Murray, J.A. Rice, C.M. Trautwein, X. Shi, R.A. Farrell, J. Bascuiian, R.E. Hintz, S.P. Mehta, N. Aversa, J.A. Ebert, B.A. Bednar, D.J. Neder, A.A. McIlheran, P.C. Michel, J.J. Nemec, E.F. Pleva, R.C. Longsworth, R.C. Johnson, R.H. Jones, J.K. Nelson, R.C. Degeneff, S.J. Salon, "Performance of a 1-MVA HTS demonstration transformer," IEEE Transactions on Applied Superconductivity, vol. 9, no. 2, pp. 680-684, 1999.

[561] E. Floch, P. Hiebel, Y. Laumond, A. Lacaze, "Modelization and test of a $500 \mathrm{~J}$ superconducting pulsed power transformer," IEEE Transactions on Applied Superconductivity, vol. 9, no. 2, pp. 1289-1292, 1999.

[562] Ji-Kwang Lee, Woo-Seok kim, Song-Yop Hahn, Kyeong-Dal Choi, Gueesoo Cha, Seung-Chan Chang, "Development of a three phase $100 \mathrm{kVA}$ superconducting power transformer with amorphous cores," IEEE Transactions on Applied Superconductivity, vol. 9, no. 2, pp. 1293-1296, 1999.

[563] T. Ise, Y. Murakami, "Design method of volt/turn for minimizing life cost of a superconducting transformer," IEEE Transactions on Applied Superconductivity, vol. 9, no. 2, pp. 1297-1299, 1999.

[564] H. Yamaguchi, T. Kataoka, Y. Sato, “Analysis of a 3-phase air-core superconducting power transformer," IEEE Transactions on Applied Superconductivity, vol. 9, no. 2, pp. 1300-1303, 1999.

[565] A.H. Miklich, J.X. Przybysz, T.J. Smith, S.P. Benz, T.E. Harvey, "Superconducting thin-film transformers at microwave frequencies," IEEE Transactions on Applied Superconductivity, vol. 9, no. 2, pp. 3062-3065, 1999.

[566] Y. Zhang, H. R.Yi, J. Schubert, W. Zander, H.-J. Krause, H. Bousack, A.I. Braginski, "Operation of rf SQUID magnetometers with a multi-turn flux transformer integrated with a superconducting labyrinth resonator," IEEE Transactions on Applied Superconductivity, vol. 9, no. 2, pp. 3396-3400, 1999.

[567] R.M. Morais, W.A. Mannheimer, M. Carballeira, J.C. Noualhaguet, "Furfural analysis for assessing degradation of thermally upgraded papers in transformer insulation," IEEE Transactions on Dielectrics and Electrical Insulation, vol. 6, no. 2, pp. 159-163, 1999.

[568] Xuzhu Dong, Deheng Zhu, Changchang Wang, Kexiong Tan, Yilu Liu, "Simulation of transformer PD pulse propagation and monitoring for a $500 \mathrm{kV}$ substation," IEEE Transactions on Dielectrics and Electrical Insulation, vol. 6, no. 6, pp. 803-813, 1999.

[569] S.M. Alghuwainem, "Steady-state analysis of a self-excited induction generator including transformer saturation," IEEE Transactions on Energy Conversion, vol. 14, no. 3, pp. 667-672, 1999

[570] T. Funabashi, N. Takeuchi, T. Sugimoto, T. Ueda, L. Dube, A. Ametani, "Generator modeling for transformer transfer voltage study," IEEE Transactions on Energy Conversion, vol. 14, no. 4, pp. 1193-1198, 1999.

[571] H. Yamashita, V. Cingoski, E. Nakamae, "Design improvements on graded insulation of power transformers using transient electric field analysis and visualization technique," IEEE Transactions on Energy Conversion, vol. 14, no. 4, pp. 1379-1384, 1999.

[572] W.H. Kersting, W.H. Phillips, W. Carr, “A new approach to modeling three-phase transformer connections," IEEE Transactions on Industry Applications, vol. 35, no. 1, pp. 169-175, 1999.

[573] A. Hannah, "Negative-sequence relay protection for blown high-side transformer fuse detection," IEEE Transactions on Industry Applications, vol. 35, no. 1, pp. 183-189, 1999.

[574] M. Kang, B.O. Woo, P. Enjeti, I.J. Pitel, "Autoconnected-electronic-transformer-based multipulse rectifiers for utility interface of power electronic systems," IEEE Transactions on Industry Applications, vol. 35, no. 3, pp. 646-656, 1999.

[575] M.P. Oommen, J.L. Kohler, "Effect of three-winding transformer models on the analysis and protection of mine power systems," IEEE Transactions on Industry Applications, vol. 35, no. 3, pp. 670-674, 1999.

[576] W.G. Odendaal, J.A. Ferreira, "Effects of scaling high-frequency transformer parameters," IEEE Transactions on Industry Applications, vol. 35, no. 4, pp. 932-940, 1999.

[577] A.W. Kelley, S.W. Edwards, J.P. Rhode, M.E. Baran, "Transformer derating for harmonic currents: a wide-band measurement approach for energized transformers," IEEE 
Transactions on Industry Applications, vol. 35, no. 6, pp. 1450-1457, 1999.

[578] Z. Guoqiang, Z. Yuanlu, C. Xiang, “Optimal design of high voltage bushing electrode in transformer with evolution strategy," IEEE Trans. Magn., vol. 35, no. 3, pp. 1690-1693, 1999.

[579] C. Xiang, Z. Guoqiang, "Sensitivity analysis and automatic design of voltage ratio in an optical instrument voltage transformer," IEEE Trans. Magn., vol. 35, no. 3, pp. 1769-1772, 1999.

[580] B.A. Luciano, M.E. de Morais, C.S. Kiminami, "Single phase 1-kVA amorphous core transformer: design, experimental tests, and performance after annealing," IEEE Trans. Magn., vol. 35 , no. 4 , pp. 2152-2154, 1999.

[581] Li-Ling Lee, C.-L.E. Tasy, "Novel zero ripple DC current transformer design," IEEE Trans. Magn., vol. 35, no. 4, pp. 3514-3516, 1999.

[582] Dong-Hun Kim, Song-Yop Hahn, Sang-Young Kim, "Improved design of cover plates of power transformers for lower eddy current losses," IEEE Trans. Magn., vol. 35, no. 5, pp. 3529-3531, 1999.

[583] W.C. Viana, R.J. Micaleff, S. Young, S. F.P. Dawson, E.P. Dick, "Transformer design considerations for mitigating geomagnetic induced saturation," IEEE Trans. Magn., vol. 35, no. 5 , pp. 3532-3534, 1999.

[584] T. Inoue, M. Furukawa, T. Sato, "A novel transmission-line type high frequency transformer using a fine-grain $\mathrm{Mn}-\mathrm{Zn}$ ferrite [for ballasts]," IEEE Trans. Magn., vol. 35, no. 5, pp. 3538-3540, 1999.

[585] J.D. Lavers, V. Bolborici, "Loss comparison in the design of high frequency inductors and transformers," IEEE Trans. Magn., vol. 35, no. 5, pp. 3541-3543, 1999.

[586] L. Zhao, C.F. Foo, K.J. Tseng, “A new structure transcutaneous transformer for artificial heart system," IEEE Trans. Magn., vol. 35, no. 5, pp. 3550-3552, 1999.

[587] J.K. Sykulski, K.F. Goddard, R.L. Stoll, "High temperature superconducting demonstrator transformer: design considerations and first test results," IEEE Trans. Magn., vol. 35, no. 5, pp. 3559-3561, 1999.

[588] M.W. Conroy, B.D. Nelson, B. Bozoki, “C37.110 guide for the application of current transformers used for protective relaying purposes," IEEE Trans. Power Delivery, vol. 14, no. 1, pp. 94-97, 1999.

[589] M.A. Brubaker, J.K. Nelson, "Development and calibration of a network-based streaming electrification model for core-form transformer structures," IEEE Trans. Power Delivery, vol. 14, no. 2, pp. 431-436, 1999.

[590] E.F. Fuchs, Y. You, D.J. Roesler, "Modeling and simulation, and their validation of three-phase transformers with three legs under DC bias," IEEE Trans. Power Delivery, vol. 14, no. 2, pp.443-449, 1999

[591] A.H. Chowdhury, W.M. Grady, E.F.Fuchs, “An investigation of the harmonic characteristics of transformer excitation current under nonsinusoidal supply voltage," IEEE Trans. Power Delivery, vol. 14, no. 2, pp. 450-458, 1999.

[592] T.S. Sidhu, H.S. Gill, M.S. Sachdev, "A power transformer protection technique with stability during current transformer saturation and ratio-mismatch conditions," IEEE Trans. Power Delivery, vol. 14, no. 3, pp. 798-804, 1999.

[593] Kwang-Chang Lu, Nanming Chen, "A two-relay differential protective scheme for Le-Blanc transformers," IEEE Trans. Power Delivery, vol. 14, no. 3, pp. 857-862, 1999.

[594] W. Li, E. Vaahedi, Y. Mansour, "Determining number and timing of substation spare transformers using a probabilistic cost analysis approach," IEEE Trans. Power Delivery, vol. 14, no. 3, pp. 934-939, 1999.

[595] P.M. Balma, R.C. Degeneff, H.R. Moore, L.B. Wagenaar, "The effects of long term operation and system conditions on the dielectric capability and insulation coordination of large power transformers," IEEE Trans. Power Delivery, vol. 14, no. 3, pp. 960-971, 1999.

[596] D.E. Warner, W.T. Jewell, "An investigation of zero order harmonics in power transformers," IEEE Trans. Power Delivery, vol. 14, no. 3, pp. 972-977, 1999.

[597] M.A. Brubaker, S.R. Lindgren, G.K. Frimpong, J.M. Walden, "Streaming electrification measurements in a $1 / 4$-scale transformer model," IEEE Trans. Power Delivery, vol. 14, no. 3, pp. 978-785, 1999.

[598] D.A. Koppikar, S.V. Kulkarni, P.N. Srinivas, S.A. Khaparde, R. Jain, "Evaluation of flitch plate losses in power transformers," IEEE Trans. Power Delivery, vol. 14, no. 4, pp. 996-1001, 1999.

[599] M. Popov, E. Acha, "Overvoltages due to switching off an unloaded transformer with a vacuum circuit breaker," IEEE Trans. Power Delivery, vol. 14, no. 4, pp. 1317-1326, 1999.

[600] T. Leibfried, K. Feser, "Monitoring of power transformers using the transfer function method," IEEE Trans. Power Delivery, vol. 14, no. 4, pp. 1333-1341, 1999.

[601] Hong-Tzer Yang, Chiung-Chou Liao, "Adaptive fuzzy diagnosis system for dissolved gas analysis of power transformers," IEEE Trans. Power Delivery, vol. 14, no. 4, pp. 1342-1350, 1999.

[602] M. Gomez-Morante, D.W. Nicoletti, "A wavelet-based differential transformer protection," IEEE Trans. Power Delivery, vol. 14, no. 4, pp. 1351-1358, 1999.

[603] T.K. Saha, M. Darveniza, Z.T. Yao, D.J.T. Hill, G. Yeung, "Investigating the effects of oxidation and thermal degradation on electrical and chemical properties of power transformers insulation," IEEE Trans. Power Delivery, vol. 14, no. 4, pp. 1359-1367, 1999.

[604] B.A. Mork, "Five-legged wound-core transformer model: derivation, parameters, implementation and evaluation," IEEE Trans. Power Delivery, vol. 14, no. 4, pp. 1519-1526, 1999.

[605] K.S. Smith, L. Ran, B. Leyman, "Analysis of transformer inrush transients in offshore electrical systems," IET Gener. Transm. Distrib., vol. 146, no. 1, pp. 89-95, 1999.

[606] Y. Shibuya, S. Fujita, T. Shimomura, "Effects of very fast transient overvoltages on transformer," IET Gener. Transm. Distrib., vol. 146, no. 5, pp. 459-464, 1999.

[607] E.F. Fuchs, D. Yildirim, T. Batan, "Innovative procedure for measurement of losses of transformers supplying nonsinusoidal loads," IET Gener. Transm. Distrib., vol. 146, no. 6, pp. 
617-625, 1999.

[608] A.F. Atkins, D.W. Auckland, B.P. Axcell, B.R. Varlow, "Novel winding for a gas-insulated transformer," IET Science Measurement \& Technology, vol. 146, no. 3, pp. 147-152, 1999.

[609] Y. Le Floch, C. Guérin, D. Boudaud, G. Meunier, X. Brunotte, "A current transformer modeling," COMPEL, vol. 21, no. 4, pp. 505-511, 2000 .

[610] H. Kanayama, R. Shioya, D. Tagami, S. Matsumoto, "3-D eddy current computation for a transformer tank," COMPEL, vol. 21 , no. 4, pp. 554-562, 2000.

[611] K.W.E. Cheng, K.F. Kwok, S.L. Ho, Y.L. Ho, “Calculation of winding losses using matrix modeling of high frequency transformer," COMPEL, vol. 21, no. 4, pp. 573-580, 2000.

[612] Z. Moravej, D. N. Vishwakarma, S. P. Singh, "Digital Filtering Algorithms for the Differential Relaying of Power Transformer: An Overview," Electric Power Components and Systems, vol. 28, no. 6, pp. 485-500, 2000.

[613] Z. Moravej, D. N. Vishwakarma, S. P. Singh, "ANN-Based Protection Scheme for Power Transformer," Electric Power Components and Systems, vol. 28, no. 9, pp. 875-884, 2000.

[614] S. C. Tripathy, E. Lakervi, "Evaluation of Transformer Loading Above Nameplate Rating," Electric Power Components and Systems, vol. 28, no. 10, pp. 971-980, 2000.

[615] T. S. Sidhu, H. S. Gill, M. S. Sachdev, “A numerical technique based on symmetrical components for protecting three-winding transformers," Electric Power Systems Research, vol. 54, no. 1, pp. 19-28, 2000.

[616] T.-H. Chen, W.-C. Yang, T.-Y. Guo, G.-C. Pu, "Modelling and analysis of asymmetrical three-phase distribution transformer banks with mid-tap connected to the secondary neutral conductor," Electric Power Systems Research, vol. 54, no. 1, pp. 83-89, 2000.

[617] E. Mombello, K. Möller, "Impedances for the calculation of electromagnetic transient phenomena and resonance in transformer windings," Electric Power Systems Research, vol. 54, no. 2, pp. 131-138, 2000.

[618]Z. Wang, Y. Liu, P.J. Griffin, "Neural net and expert system diagnose transformer faults," IEEE Computer Applications in Power Magazine, vol. 13, no. 1, pp. 50-55, 2000.

[619] A. Apostolov, B. Vandiver, "Automatic test system advances transformer protection," IEEE Computer Applications in Power Magazine, vol. 13, no. 2, pp. 31-36, 2000.

[620] B.W. McConnell, "Transformers - A successful application of high temperature superconductors," IEEE Transactions on Applied Superconductivity, vol. 10, no. 1, pp. 716-720, 2000.

[621] Kyeong Dal Choi, Hee Joon Lee, Gueesoo Cha, "Test of a high $\mathrm{T}_{\mathrm{c}}$ superconducting power transformer," IEEE Transactions on Applied Superconductivity, vol. 10, no. 1, pp. 853-856, 2000.

[622] Jungwook Sim, Gueesoo Cha, Ji-Kwang Lee, "Performance evaluation of an HTS transformer using finite element method," IEEE Transactions on Applied Superconductivity, vol. 10, no. 1, pp. 857-860, 2000.

[623] E. Gulski, H.P. Burger, G.H. Vaillancourt, R. Brooks, ”PD pattern analysis during induced test of large power transfor- mers," IEEE Transactions on Dielectrics and Electrical Insulation, vol. 7, no. 2, pp. 95-101, 2000.

[624] S. Mofizul Islam, T. Wu, G. Ledwich, "A novel fuzzy logic approach to transformer fault diagnosis," IEEE Transactions on Dielectrics and Electrical Insulation, vol. 7, no. 2, pp. 177-186, 2000

[625] P.E. Sutherland, "Application of transformer ground differential protection relays," IEEE Transactions on Industry Applications, vol. 36, no. 1, pp. 16-21, 2000.

[626] W.H. Kersting, J.S. Rathbun, "The analysis of an ungrounded Wye-Delta transformer bank serving an induction motor and single-phase lighting loads," IEEE Transactions on Industry Applications, vol. 36, no. 1, pp. 39-45, 2000.

[627] R. Morrison, M.G. Egan, "A new power-factor-corrected single-transformer UPS design," IEEE Transactions on Industry Applications, vol. 36, no. 1, pp. 171-179, 2000.

[628] A. Akdag, I. Cadirci, E. Nalcaci, M. Ermis, S. Tadakuma, "Effects of main transformer replacement on the performance of an electric arc furnace system," IEEE Transactions on Industry Applications, vol. 36, no. 2, pp. 649-658, 2000 .

[629] R.O.C. Lyra, B.J. Cardoso Filho, V. John, T.A. Lipo, "Coaxial current transformer for test and characterization of high-power semiconductor devices under hard and soft switching," IEEE Transactions on Industry Applications, vol. 36, no. 4, pp. 1181-1188, 2000.

[630] D.J. Tylavsky, Qing He, Jennie Si, G.A McCulla, J.R. Hunt, "Transformer top-oil temperature modeling and simulation," IEEE Transactions on Industry Applications, vol. 36, no. 5, pp. 1219-1225, 2000.

[631] D. Doan, J. Crouse, N.K. Haggerty, M. Ristic, "Design and protection of captive motor-transformers," IEEE Transactions on Industry Applications, vol. 36, no. 6, pp. 1704-1714, 2000.

[632] C. Nussbaum, H. Pfutzner, Th. Booth, N. Baumgartinger, A. Ilo, M. Clabian, "Neural networks for the prediction of magnetic transformer core characteristics," IEEE Trans. Magn., vol. 35, no. 1, pp. 313-329, 2000.

[633] C. Lee, H.-K. Jung, "Nonlinear analysis of the three-phase transformer considering the anisotropy with voltage source," IEEE Trans. Magn., vol. 36, no. 2, pp. 491-499, 2000.

[634] C. Lee, H.-K. Jung, "Two-dimensional analysis of three-phase transformer with load variation considering anisotropy and overlapped stacking," IEEE Trans. Magn., vol. 36, no. 4, pp. 693-696, 2000.

[635] Y. Higuchi, M. Koizumi, "Integral equation method with surface impedance model for $3 \mathrm{D}$ eddy current analysis in transformers," IEEE Trans. Magn., vol. 36, no. 4, pp. 774-779, 2000.

[636] D. Ioan, I. Munteanu, "Models for capacitive effects in iron core transformers," IEEE Trans. Magn., vol. 36, no. 4, pp. 990-994, 2000.

[637] X. Dexin, Y. Xiuke, Y. Yingying, "Circulating current computation and transposition design for large current winding of transformer with multi-section strategy and hybrid optimal method," IEEE Trans. Magn., vol. 36, no. 4, pp. 1014-1017, 2000. 
[638] N. Takahashi, T. Kitamura, M. Horii, J. Takehara, "Optimal design of tank shield model of transformer," IEEE Trans. Magn., vol. 36, no. 4, pp. 1089-1093, 2000.

[639] J.K. Sykulski, K.F. Goddard, R.L. Stoll, "A method of estimating the total AC loss in a high-temperature superconducting transformer winding," IEEE Trans. Magn., vol. 36, no. 4, pp. 1183-1187, 2000.

[640] N. Soda, M. Enokizono, "Improvement of T-joint part constructions in three-phase transformer cores by using direct loss analysis with E\&S model," IEEE Trans. Magn., vol. 36, no. 4 , pp. $1285-1288,2000$.

[641] J. Driesen, G. Deliege, R. Belmans, K. Hameyer, “Coupled thermo-magnetic simulation of a foil-winding transformer connected to a nonlinear load," IEEE Trans. Magn., vol. 36, no. 4, pp. 1381-1385, 2000.

[642] T. Renyuan, W. Shenghui, L. Yan, "Transient simulation of power transformers using 3D finite element model coupled to electric circuit equations," IEEE Trans. Magn., vol. 36, no. 4, pp. 1417-1420, 2000.

[643] Xiang Cui, Guoqiang Zhang, "Automatic design of impedance in shell-form power transformer," IEEE Trans. Magn., vol. 36 , no. 4, pp. 1822-1825, 2000.

[644] M. Rizzo, A. Savini, J. Turowski, "Influence of flux collectors on stray losses in transformers," IEEE Trans. Magn., vol. 36, no. 4, pp. 1915-1918, 2000.

[645] S. Clenet, J. Cros, I. Haouara, "A direct identification method of the hysteresis model for the design of SMC transformers," IEEE Trans. Magn., vol. 36, no. 4, pp. 3466-3469, 2000.

[646] S. Salon, B. LaMattina, K. Sivasubramaniam, "Comparison of assumptions in computation of short circuit forces in transformers," IEEE Trans. Magn., vol. 36, no. 5, pp. 3521-3523, 2000.

[647] Fu Wong, Junwei Lu, "High frequency planar transformer with helical winding structure," IEEE Trans. Magn., vol. 36, no. 5, pp. 3524-3526, 2000.

[648] C. Chakraborty, M. Ishida, "Performance of a series-parallel resonant DC/DC converter configured around an inductor-transformer utilizing transformer magnetics," IEEE Trans. Magn., vol. 36, no. 5, pp. 3527-3529, 2000.

[649] B. Weiser, H. Pfutzner, J. Anger, "Relevance of magnetostriction and forces for the generation of audible noise of transformer cores," IEEE Trans. Magn., vol. 36, no. 5, pp. 3759-3777, 2000.

[650] A. Schellmanns, P. Fouassier, J.-P. Keradec, J.-L.Schanen, "Equivalent circuits for transformers based on one-dimensional propagation: accounting for multilayer structure of windings and ferrite losses," IEEE Trans. Magn., vol. 36 , no. 5 , pp. 3778-3784, 2000.

[651] M. Kezunovic, Yong Guo, "Modeling and simulation of the power transformer faults and related protective relay behavior," IEEE Trans. Power Delivery, vol. 15, no. 1, pp. 44-50, 2000.

[652] U.D. Annakkage, P.G. McLaren, E. Dirks, "A current transformer model based on the Jiles-Atherton theory of ferromagnetic hysteresis," IEEE Trans. Power Delivery, vol. 15, no. 1, pp. $57-61,2000$.
[653] D.A. Tziouvaras, P. McLaren, G. Alexander, "Mathematical models for current, voltage, and coupling capacitor voltage transformers," IEEE Trans. Power Delivery, vol. 15, no. 1, pp. 62-72, 2000.

[654] E.F. Fuchs, D. Yildirim, W.M. Grady, "Measurement of eddy-current loss coefficient $\mathrm{P}_{\mathrm{EC}-\mathrm{R}}$, derating of single-phase transformers, and comparison with $\mathrm{K}$-factor approach," IEEE Trans. Power Delivery, vol. 15, no. 1, pp. 148-154, 2000.

[655] M.F. Lachman, W. Walter, P.A. von Guggenberg, "On-line diagnostics of high-voltage bushings and current transformers using the sum current method," IEEE Trans. Power Delivery, vol. 15, no. 1, pp. 155-162, 2000.

[656] A.H. Al-Haj, I. El-Amin, "Factors that influence transformer no-load current harmonics," IEEE Trans. Power Delivery, vol. 15, no. 1, pp. 163-166, 2000.

[657] E.E. Mombello, K. Moller, "New power transformer model for the calculation of electromagnetic resonant transient phenomena including frequency-dependent losses," IEEE Trans. Power Delivery, vol. 15, no. 1, pp. 167-174, 2000.

[658] D.J. Tylavsky, Qing He, G.A. McCulla, J.R. Hunt, "Sources of error in substation distribution transformer dynamic thermal modeling," IEEE Trans. Power Delivery, vol. 15, no. 1, pp. $178-185,2000$.

[659] D. Yildirim, E.F. Fuchs, "Measured transformer derating and comparison with harmonic loss factor $\left(\mathrm{F}_{\mathrm{HL}}\right)$ approach," IEEE Trans. Power Delivery, vol. 15, no. 1, pp. 186-191, 2000.

[660] J.A. Ebert, "Power transformer operation at over and underexcitation, benefits and consequences," IEEE Trans. Power Delivery, vol. 15, no. 1, pp. 192-197, 2000.

[661] G.E. Mechler, R.S. Girgis, "Magnetic flux distributions in transformer core joints," IEEE Trans. Power Delivery, vol. 15, no. 1, pp. 198-203, 2000.

[662] E.G. teNyenhuis, G.F. Mechler, R.S. Girgis, "Flux distribution and core loss calculation for single phase and five limb three phase transformer core designs," IEEE Trans. Power Delivery, vol. 15, no. 1, pp. 204-209, 2000.

[663] J.A. Jardini, H.P. Schmidt, C.M.V. Tahan, "Distribution transformer loss of life evaluation: a novel approach based on daily load profiles," IEEE Trans. Power Delivery, vol. 15, no. 1, pp. 361-366, 2000.

[664] T.K. Hamrita, "Repetitive learning control for the correction of wound-type potential transformer measurement errors: sensitivity analysis," IEEE Trans. Power Delivery, vol. 15, no. 2, pp. 461-466, 2000.

[665] U.D. Anndkkage, Ming Yu, P.G. Mclaren, E. Dirks, A.D. Parker, "Simulation of a differential current protection scheme involving multiple current transformers," IEEE Trans. Power Delivery, vol. 15, no. 2, pp. 515-519, 2000.

[666] J. Faiz, M. Ojaghi, "Novel techniques for treating singularity problems in the boundary element method applied to electric field evaluation within the tank of a power transformer," IEEE Trans. Power Delivery, vol. 15, no. 2, pp. 592-598, 2000 .

[667] M. Yamamoto, M. Yamaguchi, K. Kaiho, "Superconducting transformers," IEEE Trans. Power Delivery, vol. 15, no. 2, pp. 599-603, 2000 . 
[668] Zhiqian Bo, G. Weller, T. Lomas, "A new technique for transformer protection based on transient detection," IEEE Trans. Power Delivery, vol. 15, no. 2, pp. 870-875, 2000.

[669] T. Rajakanthan, A.S. Meyer, B. Dwolatzky, "Computer generated transformer zones as part of township electrification design software," IEEE Trans. Power Delivery, vol. 15, no. 2, pp. 1067-1072, 2000.

[670] N. Locci, C. Muscas, "A digital compensation method for improving current transformer accuracy," IEEE Trans. Power Delivery, vol. 15, no. 4, pp. 1104-1109, 2000.

[671] T.K. Hamrita, B.S. Heck, A.P.S. Meliopoulos, "On-line correction of errors introduced by instrument transformers in transmission-level steady-state waveform measurements," IEEE Trans. Power Delivery, vol. 15, no. 4, pp. 1116-1120, 2000.

[672] M.A. Brubaker, J.K. Nelson, “A parametric study of streaming electrification in a full-scale core-form transformer winding using a network-based model," IEEE Trans. Power Delivery, vol. 15, no. 4, pp. 1118-1192, 2000.

[673] Xusheng Chen, "Negative inductance and numerical instability of the Saturable Transformer Component in EMTP," IEEE Trans. Power Delivery, vol. 15, no. 4, pp. 1199-1204, 2000.

[674] Q., He, J. Si, D.J. Tylavsky, "Prediction of top-oil temperature for transformers using neural networks," IEEE Trans. Power Delivery, vol. 15, no. 4, pp. 1205-1211, 2000.

[675] D.A. Koppikar, S.V. Kulkarni, J. Turowski, "Fast 3-dimensional interactive computation of stray field and losses in asymmetric transformers," IET Gener. Transm. Distrib., vol. 147, no. 4, pp. 197-201, 2000.

[676] E.F. Donaldson, J.R. Gibson, G.R. Jones, "Hybrid optical current transformer with optical and power-line energisation," IET Gener. Transm. Distrib., vol. 147, no. 5, pp. 304-309, 2000.

[677] M.K. Abdul Rahman, R. Arora, S.C. Srivastava, "Partial discharge classification using principal component transformation," IET Science Measurement \& Technology, vol. 147, no. 1, pp. 7-13, 2000.

[678] Y. Lu, X. Tan, X. Hu, "PD detection and localisation by acoustic measurements in an oil-filled transformer," IET Science Measurement \& Technology, vol. 147, no. 2, pp. 81-85, 2000.
[679] R.J. Heywood, A.M. Emsley, M. Ali, "Degradation of cellulosic insulation in power transformers. Part 1: Factors affecting the measurement of the average viscometric degree of polymerisation of new and aged electrical papers," IET Science Measurement \& Technology, vol. 147, no. 2, pp. 86-90, 2000 .

[680] A.M. Emsley, X. Xiao, R.J. Heywood, M. Ali, "Degradation of cellulosic insulation in power transformers. Part 2: Formation of furan products in insulating oil," IET Science Measurement \& Technology, vol. 147, no. 2, pp. 110-114, 2000.

[681] A.M. Emsley, X. Xiao, R.J. Heywood, M. Ali, "Degradation of cellulosic insulation in power transformers. Part 3: Effects of oxygen and water on ageing in oil," IET Science Measurement \& Technology, vol. 147, no. 3, pp. 115-119, 2000.

[682] Z.D. Wang, P.A. Crossley, K.J. Cornick, D.H. Zhu, "Partial discharge location in power transformers," IET Science Measurement \& Technology, vol. 147, no. 5, pp. 249-255, 2000.

[683] A.M. Emsley, R.J. Heywood, M. Ali, X. Xiao, "Degradation of cellulosic insulation in power transformers. Part 4: Effects of ageing on the tensile strength of paper," IET Science Measurement \& Technology, vol. 147, no. 6, pp. 285-290, 2000.

[684] P. L. Mao, R. K. Aggarwal, "A wavelet transform based decision making logic method for discrimination between internal faults and inrush currents in power transformers," International Journal of Electrical Power \& Energy Systems, vol. 22, no. 6, pp. 389-395, 2000.

[685] Tsai-Hsiang Chen, Jeng-Tyan Cherng, "Evaluation of load division among transformers of different capacities in the grounded wye-delta and open wye-open delta banks under balanced loading and various power factor conditions," International Journal of Electrical Power \& Energy Systems, vol. 22, no. 8, pp. 563-573, 2000.

[686] Q. Wu, D. H. Popović, D. J. Hill, “Avoiding sustained oscillations in power systems with tap changing transformers," International Journal of Electrical Power \& Energy Systems, vol. 22, no. 8, pp. 597-605, 2000.

[687] G. Krismanić, H. Pfützner, N. Baumgartinger "On the practical relevance of rotational magnetisation for power losses of transformer cores," Journal of Magnetism and Magnetic Materials, vol. 215-216, pp. 150-152, 2000. 